\title{
Operator lowering
}

PIETER A. M. SEUREN

\section{Abstract}

Since the late 1960s a variety of theories has been proposed for the grammatical treatment of quantifiers in natural-language sentences. In the linguistic tradition of transformational grammar the so-called lowering analysis was proposed (Lakoff 1969; McCawley 1973: ch. 14, 17, 18). Very soon after that Montague's famous analysis of quantifiers known as the PTQ analysis was presented (Montague 1974). And recently the theory of generalized quantifiers (Barwise and Cooper 1981) has appeared on the scene. It is a remarkable fact that, whatever the merits of these respective theories, relatively little is found in the literature in the way of linguistic argumentation for or against any of them. The lowering analysis was supported by some arguments when it was first presented, but no attempt is to be found in the literature to show its syntactic merits in more than a cursory way (McCawley 1981: 125-136 contains some material for argument but it can easily be expanded upon). Likewise, no serious argument exists in the published literature against the lowering analysis (with the possible exception of Jackendoff 1983: 242). The PTQ analysis was never supported by anything approaching a linguistic argument; its status was based primarily on the fact that this analysis provided the means for $a$ formal truth-conditional semantic calculus, an aspect badly neglected in the linguistically flavored lowering analysis. As regards the analysis in terms of generalized quantifiers, its linguistic motivation is based on the claim that this theory alone can account for complex quantifiers like more than half, most, finitely many, but there is no argument that the other analyses cannot do the same, nor is it shown that this analysis has any advantages from the point of view of linguistic explanation. The present paper again takes up the case of the lowering analysis, not only for quantifiers but also for other logical operators such as negation, conjunction, and certain lexical representatives of modalities, as well as for contrastively accented NPs or larger constituents. The case is supported by the kind of linguistic argument that 
shows what is gained in the way of generalized, and therefore explanatory, description when the lowering analysis is accepted. $A$ variety of observations is presented, all problematic in their own right but (largely) regular in the light of the lowering analysis. The argumentation is meant not only as a defense of the lowering analysis but also as a challenge to any alternative treatment of quantifiers and/or other logical operators.

\section{Some historical backgrounds of the lowering analysis}

In the history of Western linguistic analysis there are two distinct but not totally unrelated traditions, the grammatical tradition and the logical tradition. In the grammatical tradition, which originated in classical antiquity as an application for practical (normative) purposes of the existing standard system of logical analysis, quantifiers never occupied a special place: they were not recognized as a separate category. But in the logical tradition they were. In the Aristotelian system of predicate calculus (APC) the general distinction between subject and predicate was applied, and, as we shall see presently, a calculus was developed that took into account only quantified subjects, not other nominal constituents under a quantifier. Traditional grammar owes its parsing method mainly to this Aristotelian tradition of the subject-predicate distinction, but since grammar was (and remained for a long time) an applied and normative discipline, not at all concerned with the logical calculus of entailments, no need was felt to distinguish quantified subjects as a separate category. Quantified NPs were considered to have the same structure as nonquantified NPs, and quantifying determiners were not taken to differ in any essential way from definite determiners such as the definite article or demonstrative or possessive pronouns.

With the advent of modern quantification theory (QT), around the turn of the century, important changes came about in logical but not in grammatical analysis. In logical analysis $n$-ary predicate structure (not just subject and predicate) was restricted to atomic formulae, and a great deal of 'superstructure' in the form of scope-bearing quantifying operators was added. The current forms of grammatical analysis were not affected at all by this development in logic. In fact, grammarians and logicians had come to belong to very different worlds, and hardly any mutual influencing took place. This changed in the 1960 s, a period that witnessed the birth both of formal semantics and of semantic syntax (often called 'generative semantics'). In both these developments theories were developed to relate grammatical structure to logical structure, whereby formal semantics started from the logical and semantic syntax 
from the grammatical end. Both schools agreed in their appreciation of modern QT: the expressive and logical power of the system of QT is, apparently, so great that it is felt to be indispensable for any serious semantics. In formal semantics, however, unrestricted quantification theory (UQT) has always been preferred, clearly because of its simple and elegant logical properties (which made Russell opt for UQT as well). In semantic syntax, on the other hand, restricted quantification theory (RQT) was considered favorite, mainly because the linguistic fit of RQT is a great deal better than with UQT. The two approaches differ also in other respects. The formal semantics analyses have in common that they attempt to reconcile the grammatical (or 'surface') form of sentences containing quantified NPs with analyses in terms of UQT by formulating ordered rules of composition, whereby bound variables are replaced by full quantified NPs in a certain order (thus reflecting scope hierarchies), and by providing 'translations' for the quantified NPs in terms of lambda calculus (thus reflecting UQT analyses). They moreover follow Russell (1905) in that all NPs (with the possible exception of proper names) are considered to be quantified.

In semantic syntax a totally different procedure was followed. Here a separate level of syntactic and lexical representation was invoked, differing from the surface representation and structured strictly in terms in RQT. Transformational mapping rules relate the two levels systematically. Definite terms are not considered to be quantified. Scope hierarchies are expressed at the level of 'deep' or 'semantic' representation in the way such hierarchies are expressed in RQT. The quantifiers, as well as other operators, are lowered, by the transformational process or rule schema of lowering, into the propositional 'nucleus' (cf. Seuren 1969). The claim made by those who proposed the lowering analysis in the 1960s, and repeated here with stronger arguments, is that the transformational processes required for a regular mapping of RQT analyses onto surface structures are for the most part independently required in syntax for the adequate specification of grammatical structures and, to the extent that they may not be independently required, fall within the constraints that seem to hold for transformational rules generally. The lowering analysis thus claims a substantial advantage on account of greater explanatory value. The present paper aims at elucidating this point by producing better and stronger arguments than were produced in the earlier years. An interesting corollary is that, after all, the grammatical and the logical traditions of linguistic analysis are seen to converge again, after centuries of independent development, and may even be expected to coalesce.

Let us now look at the history of this question in greater detail, starting with Aristotle's system of predicate calculus (APC) known as the square of 
oppositions. This system, though of course a monumental achievement, suffered from serious logical weaknesses. APC deals exclusively with sentences whose subjects are either existentially or universally quantified (plus negation) and leaves out of account sentences containing definite terms (individual names). Four types of quantified sentences are distinguished:
All $F$ is $G$
Some $F$ is $G$ (type $I$ )
No $F$ is $G \quad$ (type $E$ )
Some $F$ is not $G$ (type $O$ )

These are arranged in the so-called 'square of oppositions', Figure 1. This square symbolizes the theorems that are fundamental to APC:
a. $\mathrm{A} \equiv \neg \mathrm{O}$ (Hence: $\neg \mathrm{A} \equiv \mathrm{O}$ ) : $\mathrm{A}$ and $\mathrm{O}$ are contradictories
b. $\mathrm{E} \equiv \neg \mathrm{I}$ (Hence: $\neg \mathrm{E} \equiv \mathrm{I}$ ) : $\mathrm{E}$ and I are contradictories
c. $\mathrm{A} \vDash \neg \mathrm{E}: \mathrm{A}$ and $\mathrm{E}$ are contraries (cannot both be true)
d. $\neg \mathrm{I} \models \mathrm{O}: \mathrm{I}$ and $\mathrm{O}$ are subcontraries (cannot both be false)
e. $A \vDash I$
f. $E \models O$

From a logical point of view this system suffers from a few serious weaknesses. The first, and most important, is that the Aristotelian square collapses when the class that is quantified over universally (the 'U-class') is empty, as when it is said that

(1) All mermaids are intelligent.

in this world. When this sentence is valued 'true', then, according to theorem (e), it should follow that some mermaids are intelligent, and hence that the class of mermaids is not empty, which is not true in the model. The same conclusion follows from theorem (c), since $\neg \mathrm{E} \equiv \mathrm{I}$. The value 'true' can, therefore, not be assigned. But if (1) is valued 'false', then it follows, by theorem (a), that some mermaids are not intelligent, and hence, again, that there are mermaids. Thus, sentences quantifying over empty U-classes are neither true nor false (or both true and false), according to the square. This has the curious consequence that this logic is

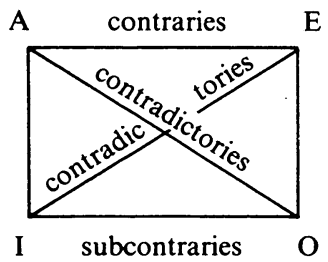

Figure 1. Square of oppositions 
limited to models with nonempty U-classes, or else the logic will violate Aristotle's own principle of the excluded third (PET), which says that all sentences considered in the logic are either true or false, without any third option.

Another weakness of this logic consists in the fact that it fails to provide an analysis, and thus a calculus, for other forms of quantification than those given in the square. For example, a sentence like

(2) No European loves all animals.

cannot be analyzed in such a way that, e.g.,

(3) For all Europeans there is some animal they don't love.

is seen to follow logically. The expressive power of this logic is thus more limited than would seem desirable.

From a linguistic point of view, however, the weaknesses of this analysis are almost negligible. As has been said, Aristotelian predicate calculus, apart from being an instrument for logical calculus, also served a linguistic purpose: the analyses provided for purposes of computing valid consequences (entailments) proved to be useful for an understanding of grammatical structure as well. Also, the entailments specified in the square strike one as intuitively plausible. Yet, taken together, they lead to paradox.

For if it is true that all doors of a house were locked, it is felt to follow that the house in question had doors (the U-class of doors is nonempty). Therefore, if the house in question had no doors, the sentence saying that all of its doors were locked must be deemed false. At the same time, however, the linguistic negation of that sentence

(4) a. Not all doors were locked.

is felt to be equivalent with the O-form,

(4) b. Some doors were not locked.

which means that if there were no doors, (4b) is false, and hence the sentence

(4) c. All doors were locked.

is true. Linguistic intuition thus seems to support a paradox in the corresponding logic.

Yet the linguistic analysis of sentences has, through the ages, happily relied on the Aristotelian subject-predicate analysis which is so fundamental to precisely the logic that harbors the pernicious paradox. It's no use here to deny this logic applicability in such cases, since the linguistic 
intuitions create a logical situation. The linguists, however, did not worry too much about the logical problems. That worry was left to the logicians.

These, as is well known, somewhat belatedly did something about it. After well over 20 centuries a principle was discovered that revolutionized logical thinking about quantified phrases. This principle consisted in 'factorizing out' the existential and the universal quantifiers and having them bind variables in propositional functions. This made it possible to concatenate quantifiers and place the negation anywhere before or after them. After Frege's pioneering work in this respect (1879), Russell perfected both the notation and the analysis, thereby creating present-day quantification theory.

What is directly relevant in this context is the distinction between two forms of quantificational analysis, restricted quantification theory and unrestricted quantification theory. In RQT each variable in each quantified proposition carries with it a specification of its domain. Thus, sentence (2) above gets the analysis

$\neg \exists \mathrm{x}:$ European $\forall \mathrm{y}:$ Animal $[\operatorname{love}(\mathrm{x}, \mathrm{y})]$

or, in words, 'it is not so that there is a European $\mathrm{x}$ such that for all animals $y$ it is the case that $x$ loves $y$ '.

The analysis in terms of RQT has the logical advantage that its expressive power is considerably increased when compared with APC: any argument of an $n$-ary predicate can now be quantified over and taken account of in the calculus. However, RQT still suffers from the other great defect of APC: it fails to account adequately for sentences with universal quantification over empty U-classes. If for each use of RQT it is specified what the universe of discourse is to be, and if it is required that the domain of each variable should consist of a subpart of the universe of discourse, then such sentences are automatically ruled out as falling outside the calculus. For example, let the universe of discourse be the actual world; then the RQT analysis of sentence (1) above,

a. $\forall \mathrm{x}:$ Mermaid [intelligent( $\mathrm{x})$ ],

is meaningless within the calculus, since the domain of the variable $x$ is not a subpart of the universe of discourse. If, on the other hand, no universe of discourse is to be specified for each use of the RQT calculus, it is not clear what truth value should be assigned to (6a) or (1). Any truthvalue assignment will then have to be made by fiat.

UQT gets around this last problem by stipulating that every variable in every proposition containing quantified phrases always ranges over the whole universe of discourse. In UQT the specification of a universe of discourse is indispensable if truth values are to be assigned. What is 
considered the domain of a specific variable is now expressed in a separate propositional function, concatenated by the functor and $(\wedge)$ for existential quantification and by the implication $(\supset)$ for universal quantification. Sentence (1) is now analyzed as

(b) b. $\forall x[$ mermaid( $x) \supset$ intelligent (x)]

and a sentence like (7a) now gets the analysis ( $7 b)$ :

(7) a. Some Europeans are brave.

b. $\exists x$ [European $(x) \wedge$ brave $(x)]$

The analysis (6b) is said to be true if and only if for every substitution of the variable $x$ in the complex propositional function between square brackets by a name of an individual in the universe of discourse a true sentence emerges. And (7b) is true just in case there is at least one such substitution that yields truth. Thus, with the help of propositional truthfunctional calculus a truth value is assigned to (6b) - and its corresponding sentence (1). For (6b) in this world the value is now 'true', since under whatever substitution of $x$ for an individual name from the universe of discourse the antecedent of the implication will be false, there not being any mermaids in this world, and an implication with a false antecedent is always true, according to the truth table for the implication, no matter whether the consequent clause is true or false.

UQT thus provides an answer to both defects of APC mentioned above. Not only does it increase the logical expressive power of the calculus to a more acceptable level, it also assigns a clear truth value to sentences with universal quantification over empty U-classes. That truth value is 'true'. Just as in classical propositional calculus, the assignment of the value 'true' is made in all cases where there is no specific ground for the assignment of the value 'false': truth is the default value and the onus of proof lies with him who assigns falsity.

Russell, and with him virtually the whole of 20th century logic, clearly preferred UQT, for the reasons mentioned. Yet in spite of its logical merits, the linguistic merits of UQT are nil. The adoption of UQT by the world of logic resulted directly in a mutual alienation between logic and linguistics. Whereas it was already felt that the assignment of truth to all implications with false antecedents was somewhat artificial, the assignment of truth to sentences with universal quantification over empty Uclasses went downright against strong natural linguistic intuitions. Consider a man who owns a car with a diesel engine (and therefore without any spark plugs). He takes his car to a garage for a servicing and, on seeing the exorbitant bill, protests and is then told, 'But we changed all the spark plugs'. This man is simply told a lie, and there can be no 
question of the utterance made by the garage owner being true in virtue of the fact that the engine in question had no spark plugs. Truth, in other words, is not a default value. And linguistic intuition wants such sentences to be false, not true, no matter if such an assignment of truth value poses problems of a logical nature.

Moreover, logical analysis in terms of UQT has now lost its significance for linguistic analysis. Whereas the Aristotelian calculus had both a logical and a linguistic function, modern QT, and especially UQT, seemed to have lost all linguistic relevance. The relation between analyses like (6b) or (7b) and their corresponding linguistic sentences (1) and (7a) seemed far-fetched and linguistically unmotivated. Whether RQT had any linguistic merits left was hardly a question, given the obscure status of this form of quantificational analysis in the logical literature anyway.

Then, however, a startling discovery was made. After a first tentative indication in Geach (1962: 106-107), linguists discovered, in the late 1960s, that an analysis of quantified terms and of negation along the lines of modern QT, and especially RQT, is strongly relevant for syntactic description and explanation. It was found (Katz and Postal 1964; Lakoff 1969, 1971; Seuren 1967, 1969; McCawley 1970a, 1972) that there is a nontrivial correlation between logical scope of quantifiers and negation on the one hand, and the left-to-right order of the corresponding elements in linguistic surface structure. Examples like the following became well known in the literature:

(8) a. Nobody here knows two languages.

b. Two languages are known by nobody here.

(9) a. One door was not locked.

b. Not one door was locked.

Quantificational analysis of these sentences on grounds of intuitive understanding clearly reveals that the operator with the larger scope always precedes the operator with the narrower scope in surface structure. This correspondence is brought out most clearly in analyses according to RQT. The four sentences of (8) and (9) correspond, in RQT terms, to those of (10) and (11), respectively (with an existential representation for numerals $n$, requiring for truth that there are at least $n$ substitutions yielding truth):
a. $\neg \exists$ : Person $\exists 2 \mathrm{y}$ : Language $[\mathrm{know}(\mathrm{x}, \mathrm{y})]$
b. $\exists 2 \mathrm{y}$ : Language $\neg \exists \mathrm{x}$ : Person $[\mathrm{know}(\mathrm{x}, \mathrm{y})]$
a. $\exists 1 \mathrm{x}$ : Door $\neg[$ be locked(x)]
b. $\neg \exists 1 \mathrm{x}$ : Door [be locked(x)] 


\section{General formulation of lowering}

The lowering analysis can now be described in general terms as follows. Every formula of RQT contains one proposition(al function) which contains the lexical predicate $P$ plus its arguments. These are either a bound variable, a definite NP (i.e. not quantified), or an embedded clause. (A bound variable may also occur within an embedded clause, although, from a grammatical point of view, the types of clauses that can be 'quantified into' are limited, as will be shown below.) Every bound variable corresponds with a quantifier to the left of the propositional function. The quantifier (universal, existential, or any of a number of subtypes of these) carries the domain specification for the variable in question. A quantifier is lowered into the propositional function as follows: the quantifier is replaced by a lexical expression L (roughly some $N$ for the existential quantifier, and all $N$ or every $N$ for the universal quantifier, where $N$ [noun] embodies the domain specification); $\mathrm{L}$ is moved into the propositional function where it replaces the corresponding variable. This process is called 'lowering' because its grammatical description is specified in tree structures, as will be shown in the following section. The process is meant to be grammatically real, whereby the RQT formula is the underlying semantic analysis, and the lowerings are part of the transformational process.

The lowering process is cyclic in that it is always the operator just left of the propositional function which is lowered into it, until all quantifiers and other lowering operators have been 'swallowed' by the propositional function so that it is no longer a function but a full sentence. If we apply this informal machinery to ( $10 \mathrm{a})$, we see that the quantifier ' $\exists 2 \mathrm{y}$ : Language' is lowered first, yielding the new propositional function [know(x,two languages)]. Then the quantifier ' $\exists \mathrm{x}$ : Person' is lowered, yielding [know (somebody, two languages)] which is no longer a propositional function.

Not only quantifiers are lowered, other operators are lowered as well, notably the negation and other scope-bearing elements, such as sentential adverbs (perhaps, probably) and (as will be explained below) the truthfunctional connectives and and or. Verbal tenses are likewise considered to be lowering operators in semantic structure. The 'landing site' of these operators is defined by language-particular grammatical rules. In English, for example, the negation is adjoined to the verb; only if forced by the scope ordering constraint (SOC) will it go to some other permitted site. SOC says, in principle, that all lowerings must be such that the element lowered stays on the left of any element lowered earlier, in the finally resulting surface structure. Hence, the remaining negation of (10a) must stay left of somebody in surface structure, yielding nobody. 
When operators are forced into a position violating SOC, either no viable surface structure is available, or the receiving propositional structure must change its internal structure or its lexical choice or its intonation. Thus, $(10 \mathrm{~b})$ does not translate as (8a) unless special intonational means are adopted, but it translates happily as ( $8 b)$ where the propositional function has been passivized, thus placing the variables in the right order for the lowering of the quantifiers.

The following section shows in some detail how lowering can be implemented in a proper grammatical theory. The specific treatment proposed draws largely on work by McCawley, and also on Seuren (1985: ch. 2).

\section{Some technical details of lowering}

The correspondence between scope and left-to-right order is not absolute, but it is striking enough to be considered relevant. The lowering analysis for quantifiers, negation, and other operators that seem to be sensitive to this correspondence is based on the notion that the operators in question are hierarchically ordered in the underlying syntactic tree structures providing both a semantic analysis and a syntactic deep structure (let us speak of SA or semantic analysis). Following McCawley (1972), it seems best to regard the operators as semantic predicates. Proposition-forming operators, such as negation, sentential connectives, sentence adverbs, take propositional structures as arguments and quantifiers take set denotations as arguments. Schematically, an SA tree containing propositional operators will thus have the general structure of (12a) or, equivalently, $(12 b)$ or its simplified version $(12 \mathrm{c})$ :

a.

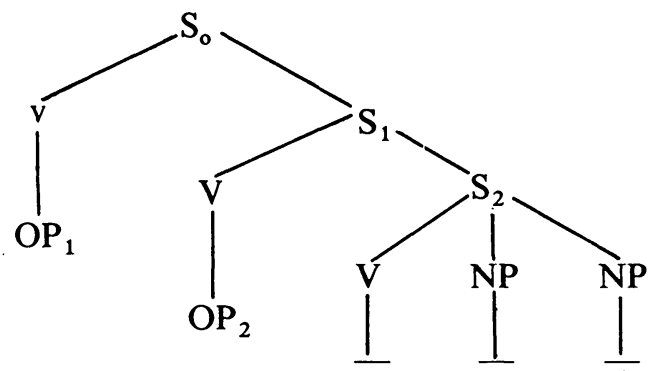

b. $\left.\left.\mathrm{S}_{\mathrm{o}}\left[\mathrm{V}^{[\mathrm{OP}} \mathrm{P}_{1}\right] \mathrm{S}_{1}\left[\mathrm{~V}^{[\mathrm{OP}} \mathrm{P}_{2}\right] \mathrm{S}_{2}[\mathrm{~V}-\mathrm{NP}-\mathrm{NP}]\right]\right]$

c. $\mathrm{OP}_{1} \mathrm{OP}_{2}[\mathrm{~V}-\mathrm{NP}-\mathrm{NP}]$

Operator lowering now consists in the cyclical lowering of each operator into the $\mathrm{S}$ forming its scope. Thus, in a structure of the form (12), $\mathrm{OP}_{2}$ is first lowered into $S_{2}$ on the $S_{1}$ cycle. Given the general principle in 
transformational grammar that any nonbranching node labeled identically with its immediately dominating node (any 'idle' node) is pruned, $S_{1}$ is pruned. Hence $S_{2}$, which now harbors $\mathrm{OP}_{2}$, becomes the new argument $\mathrm{S}$ of $\mathrm{OP}_{1}$. Now, on the $\mathrm{S}_{0}$ cycle, $\mathrm{OP}_{1}$ is lowered into its argument $\mathrm{S}$, i.e., $\mathrm{S}_{2}$. SOC, in its simplest and most general formulation, ensures that in $\mathrm{S}_{2}$, which takes in both $\mathrm{OP}_{2}$ and $\mathrm{OP}_{1}$, the latter stays to the left of the former, grammar permitting. If the grammar does not permit, and no escape clause applies, there is no corresponding surface structure.

If the operator is a propositional connective (e.g. and), the structural schema is

a.

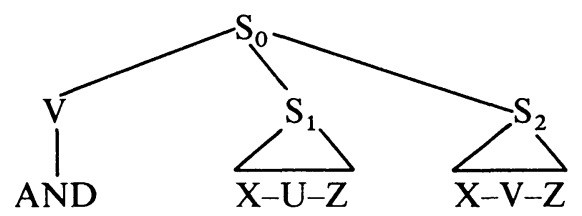

On the $S_{0}$ cycle, cyclical conjunction reduction obligatorily maps $S_{1}$ and $\mathrm{S}_{2}$ onto each other, whereby at most the identical parts collapse and at least the nonidentical parts are mapped onto a common superordinate node ('C') dominating them both, in the corresponding order, and leaving an empty slot for the connective to be lowered into. ${ }^{1}$ The result of (maximal) cyclical conjunction reduction on (13a) is thus

b.

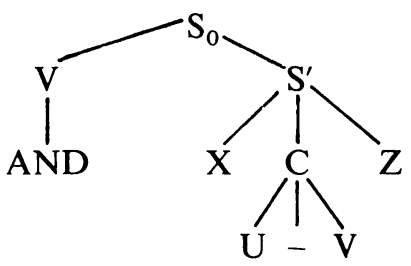

The connective predicate AND is then lowered into the empty slot ("-) between $U$ and $V$. As will be demonstrated below, such lowering of AND obeys in principle the scope ordering constraint SOC.

If the operator is a quantifier, the SA can be taken to have the following schematic form (see Seuren 1985: ch. 2): ${ }^{2}$

a.

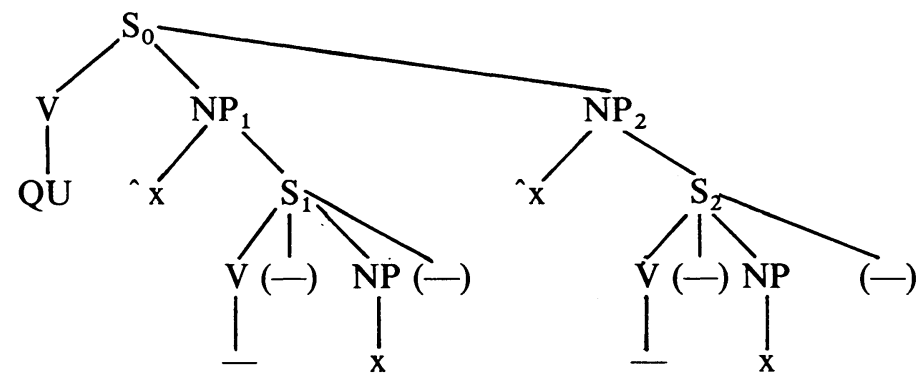


$\mathrm{NP}_{1}$ and $\mathrm{NP}_{2}$ are set-denoting terms, to be read as 'the set of $\mathrm{x}$ such that $\ldots \mathrm{x} \ldots$... A quantifier expresses a relation between sets: the existential quantifiers express the existence of a nonempty intersection between the sets denoted; the universal quantifiers express an inclusion relation of the set denoted by $\mathrm{NP}_{2}$ in the set denoted by $\mathrm{NP}_{1}$. The syntactic processing involves the following steps. On the $S_{0}$ cycle, the set-denoting operators ' ' $\mathrm{x}$ ' are lowered into the arguments $S_{1}$ and $S_{2}$, respectively:

b.

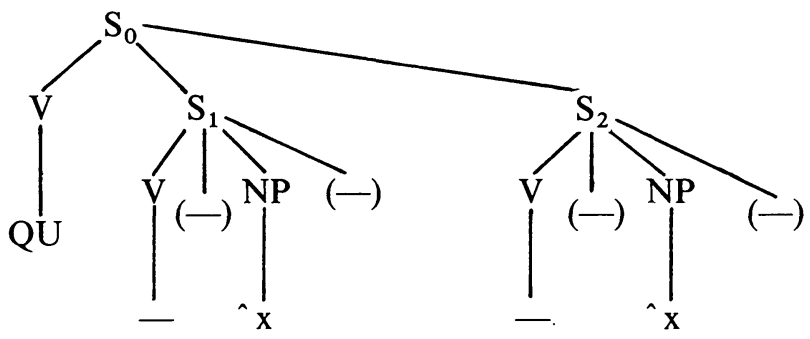

By object incorporation, $\mathrm{S}_{2}$ is made part of the quantifier QU:

(14) c.

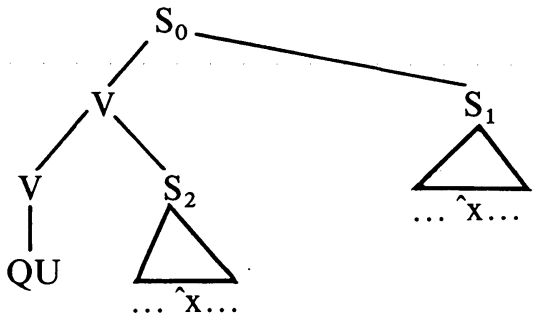

Now, the complex $\mathrm{V}$ containing the quantifier is lowered by quantifier lowering into $S_{1}$, whereby the landing site is defined by the position of the variable $x$ in $S_{1}$. The predicate of $S_{2}$ standardly becomes the noun of the quantified NP, and QU is translated as some for the basic existential quantifier $\exists$, and as all or every for the basic universal quantifier $\forall$. Thus, if QU is $\exists, S_{1}$ is [criminal $x$ ], and $S_{2}$ is [human $x$ ], the resulting sentence will be

(15) Some humans are criminals.

It is clear that this analysis of quantification in natural language is a close parallel of RQT: the structure (14c) is a direct counterpart of the format of RQT analyses, as demonstrated, for example, in (6a) above. The semantics going with the analysis differs from the semantics in classical QT, in that truth or falsity are not made dependent on substitution of variables for referring expressions in the propositional function(s), but on the relation obtaining between the sets denoted. 
UQT is indeed found to be too far removed from linguistic structure to be considered of use in linguistic analysis and description, but RQT proves to be of great value. The propositional function that comes with each RQT formula turns out to be the grammatical 'skeleton' (or, as in Seuren 1969, the nucleus) of the sentence, and the operators, including the quantifiers, are lowered into it, whereby, in principle, the left-to-right order must reflect the scope hierarchy, or, equivalently, the order of lowering. ${ }^{3}$

\section{Universal quantification over empty U-classes}

The logical problem associated with universal quantification over empty U-classes is not hereby solved, but it has become quite solvable. The solution involves a rejection of the principle of the excluded third (PET) and the introduction of a third truth value, 'radically false', besides 'minimally false' and 'true'. For a full elaboration, see Seuren (1985), where it is specified that radical falsity ensues when a presupposition is not satisfied, minimal falsity when all presuppositions are satisfied but not some classical entailment condition, and truth when all truth conditions are satisfied. The conditions in question are all associated with the predicates of the semantic analyses. Their predicate conditions fall into two classes, the preconditions which must be fulfilled by the term references of the predicate in question for the presuppositions to be fulfilled (they 'generate' the presuppositions of the sentence), and the satisfaction conditions which must be fulfilled by the term references of the predicate for the classical entailment conditions to be fulfilled (they 'generate' the remaining entailments).

For example, let the predicate bald have the precondition' that the referent of its subject term normally carries growth of some kind or pile made of some textile or is normally not smooth but beset with regular removable excrescences (a condition to be phrased, ultimately, in some 'language of perception'), and let this predicate therefore be extensional with respect to its subject term, i.e. it requires real existence of the term reference as a precondition. Let it, moreover, have the satisfaction condition that what is required by its first precondition is, in fact, absent. Then a sentence like

a. Today's weather is bald.

can hardly fail to be radically false whenever used. Likewise, Russell's famous sentence, 
(16)

b. The present king of France is bald.

is radically false when said now, or in Russell's days, since there is no really existing individual in the world answering the description 'present king of France' (nor was there one in 1905). Radically false sentences are made true by the radical negation, which is represented by an emphatically accented not in canonical negation position (for English: with the finite verb form), and preferably accompanied by a specification of the presupposition which is violated. Thus, the following sentences, with radical not, are now true:

(17) a. Today's weather is NOT bald: how can the weather be bald anyway?

b. The present king of France is Nor bald: there is no king of France!

Ordinary unmarked minimal negation leaves radical falsity unchanged but turns minimal falsity into truth. Thus, a sentence like (16c), said of a person with a hirsute scalp, is minimally false, and its minimal negation (17c) is true and entails both the existence of the man spoken about and the fact that he has hair on his head:

(16) c. Diana's favorite lover is bald.

(17) c. Diana's favorite lover is not bald.

The minimal negation may occur in other positions than the canonical position for negation:

(18) Not all humans are criminals.

The two negations are truth-functional and are defined by the following table (where 1 stands for truth, 2 for minimal falsity, and 3 for radical falsity; $\sim$ is the symbol for minimal negation, and $\simeq$ for radical negation; the table for the classical negation $\neg$ has been added for good measure it is the union of $\sim$ and $\simeq$ ):

\begin{tabular}{l|c|c|c|}
$\mathrm{A}$ & $\sim \mathrm{A}$ & $\simeq \mathrm{A}$ & $\neg \mathrm{A}$ \\
\hline 1 & 2 & 2 & 2 \\
2 & 1 & 2 & 1 \\
3 & 3 & 1 & 1 \\
\hline
\end{tabular}

The device of associating preconditions and satisfaction conditions with predicates in semantic analysis enables us to do the same for the abstract predicate $\forall$ (the universal quantifier). Let $\forall$ have the precondition that no sentence of the form $S_{1}$ but with, in the position of the bound 
variable, a definite description referring to a member of the set denoted by $\mathrm{NP}_{2}$ be radically false. (The set denoted by $\mathrm{NP}_{2}$ must consist of only really existing individuals if the predicate of $S_{1}$ is extensional with respect to the term quantified over, and may contain intensional entities, i.e. thought up, imagined, talked about, etc., entities, if the predicate of $S_{1}$ is intensional with respect to that term.) Now it follows that, in the present world, (19a) is radically false, but (19b) is true, and (19c) is minimally false:
a. All interstellar astronauts are bald.
b. All interstellar astronauts are fictitious.
c. All elderly Americans are bald.

The first sentence is radically false because the sentential schema ' $x$ is bald' will result in a radically false sentence no matter what name for any of the interstellar astronauts thought up in whatever science fiction is substituted for $x$. The second sentence is true because all such substitutions will result in truth, i.e. the set of interstellar astronauts is entirely included in the set of things fictitious. The third sentence is minimally false, since not all sentences formed from the schema ' $x$ is bald' with the name of some elderly American filled in for $x$ are radically false. Given the requirement that minimal (i.e. presupposition-preserving) not may occupy a variety of positions, whereas radical (i.e., presupposition-cancelling) not may only be in canonical position, it follows that (20a) is still radically false, $(20 b)$ is minimally false, and $(20 c)$ is true:

(20) a. Not all interstellar astronauts are bald.

b. Not all interstellar astronauts are fictitious.

c. Not all elderly Americans are bald.

But (21) is true, provided it be read with the radical negation:

(21) All interstellar astronauts are NOT bald: there ARE no such astronauts yet!

It seems that this enrichment of the logical system taken to underlie natural language use does better justice to linguistic intuitions than any of the more classical logical systems. ${ }^{4}$ It also makes it possible to keep the Aristotelian square of oppositions intact provided only minimal negation is used, and provided the sequence 'not there is an $x$ ', or $\sim \exists$ (with standing for minimal negation), is considered the transformational result, by negative raising (see Seuren 1974), of 'for all $x$ not', or $\forall \sim$. In the cases where this derivation seems inappropriate, the theorems (d) and (f) of the square of oppositions are lost. ${ }^{5}$ 
The paradox that linguistic intuitions threatened to impose on logic has now disappeared. A sentence like (1) above will now be radically false in this world, and not true, as UQT has it, and its minimal negation,

(22) Not all mermaids are intelligent.

will likewise be radically false. Truth of (1) yields truth of

(23) Some mermaids are intelligent.

since the predicate intelligent is extensional with respect to its subject term, so that there must be a set of really existing mermaids, any of whose name standing in as a subject for the variable $x$ in the schema ' $x$ is intelligent' will yield a true or a minimally false sentence.

Moreover, the basic axiom of UQT, $\forall x[F(x)] \equiv \neg \exists x \neg[F(x)]$ (and hence $\neg \forall \mathrm{x} \neg[\mathrm{F}(\mathrm{x})] \equiv \exists \mathrm{x}[\mathrm{F}(\mathrm{x})], \quad \neg \forall \mathrm{x}[\mathrm{F}(\mathrm{x})] \equiv \exists \mathrm{x} \neg[\mathrm{F}(\mathrm{x})], \quad \forall \mathrm{x} \neg[\mathrm{F}(\mathrm{x})] \equiv \neg \exists \mathrm{x}$ $[\mathrm{F}(\mathrm{x})])$ is fully maintained, provided the minimal negation is used instead of the classical negation: $\forall \mathrm{x}[\mathrm{F}(\mathrm{x})] \equiv \sim \exists \mathrm{x} \sim[\mathrm{F}(\mathrm{x})]$ (etc.). In UQT $\neg \forall \mathrm{x}$ $[F(x) \supset G(x)]$ is false when the set of all elements that have the property $F$ (i.e. the U-class) is empty, so that no existential entailment can be derived through conversion into $\exists x[F(x) \wedge \neg \mathrm{G}(\mathrm{x})]$. However, in trivalent RQT $\sim \forall \mathrm{x}: \mathrm{F}[\mathrm{G}(\mathrm{x})]$ is radically false when the U-class is empty, and its conversion $\exists x: F \sim[G(x)]$ is likewise radically false, so that again the illicit inference is stopped. Since the falsity is of the radical kind, the minimal negation does not produce truth but again radical falsity. Only if the class of Fs (the U-class) is not empty (and $\mathrm{G}$ is extensional with respect to the argument $x$ ) can $\forall \mathrm{x}: \mathrm{F}[\mathrm{G}(\mathrm{x})]$ be minimally false and its minimal negation true so that the existence of individuals with property $F$ can be inferred. The analysis thus gives the best of both the logical and the linguistic world.

\section{The argument for the lowering analysis}

The facts observed in connection with SOC are accounted for naturally by what constitutes the general idea of the lowering analysis: cyclic lowering, together with the constraint that no higher operator may be lowered over a lower one processed earlier, i.e. SOC, provides a straightforward explanation of the facts in question. The well-known difference in interpretation between actives and passives involving lowering operators, as between ( $8 a)$ and $(8 b)$, or

(24) a. Some children know all footballers.

b. All footballers are known by some children. 
is elegantly accounted for by the assumption that whatever process underlies passive is operative in the propositional function (nucleus) before any lowering has taken place, thereby enabling the lowering process to conform to SOC. ${ }^{6}$

This analysis also leaves room for a relativization of SOC insofar as that might prove necessary or desirable. For example, it seems relatively clear that the primary readings of the sentences involved in the pairs $(8 \mathrm{a}, \mathrm{b})$ and $(24 \mathrm{a}, \mathrm{b})$ conform to SOC but that the (b)-sentences marginally allow for the primary meaning of the (a)-sentences - let us say as a secondary reading. The (a)-sentences, however, do not seem to have the primary meaning of the (b)-sentences as a secondary reading. There appears to be an asymmetry in this respect. The impression of the asymmetry is reinforced by the observation that it is equally obvious in

(25) a. Every day I read some poem.

b. I read some poem every day.

or in

a. Every day the first newspaper in the world to appear.

b. The first newspaper in the world to appear every day. ${ }^{7}$

In order to account for these minor infringements on SOC it seems sufficient to state that peripheral constituents, such as the by phrase in the passive or time adverbials like every day, are allowed to take higher scope even though they occur to the right of previously lowered quantifiers. And other such special provisions will no doubt have to be made. ${ }^{8}$

Although the lowering analysis seems to be an obvious candidate for the explanation of the facts mentioned, with a properly formulated SOC to constrain the lowerings, the question arises whether there isn't perhaps also a different analysis explaining these facts equally well or even better. This question is of particular relevance since there are analyses of naturallanguage quantifiers, in particular in the Montague tradition, which might well claim to be able to account for the facts mentioned in an equally satisfactory way, so that the lowering analysis has no special advantage over the, or some, Montague-type analysis. Such analyses, as said above, are characterized by the assignment of translations to quantified phrases, together with (usually) an ordered set of composition rules. The two together make for a computable formula in, essentially, UQT terms, with the necessary support from lambda calculus in the translations provided. The translation resulting from this process must not be confused with the 'deep' or underlying form in more linguistically oriented analyses: it is nothing but a representational device in the computation of semantic values. Supporters of such analyses might well 
claim that SOC is easily incorporated into their theory, just as it is easily incorporated into the theory of cyclic transformational rules. All that is needed is a constraint ensuring that the composition procedure starts from the far right of each sentence, so that the operators with smaller scope will automatically be translated as having smaller scope.

Clearly, if the facts at our disposal were just those that have been mentioned or exemplified so far, the two competing theories would end up in a draw. But there are other facts as well, and these seem to favor the lowering analysis and not the method of analyzing sentences by composition and translation. These facts strongly suggest the inference that the proper treatment of quantification is not via the composition and translation method, which places the analysis outside the domain of grammar, but is an integral part of grammar. This inference is based on the consideration that the factorizing out of quantifiers, common to both of the competing theories, appears to be subject to conditions or constraints which have been established for grammars of natural languages on independent grounds. Therefore, the argument goes, any analysis which places the factorizing out of quantifiers outside grammar proper is bound to lose out on a set of significant generalizations. Moreover, certain facts, such as those to do with conjunction reduction, seem to pose, if not a direct threat, in any case a serious challenge to Montague-type analyses. We shall now put forward a few considerations contributing to what we have called 'the argument for the lowering analysis'. This argument will have to force a crucial decision in favor of syntactic lowering and against semantic composition and translation systems.

\subsection{Only lowered operators conform to SOC}

It is not so that all logical elements that have to be factorized out of the surface sentence to yield a logically manageable analysis suited for semantic interpretation conform to SOC. Whereas the negation follows SOC strictly, and the quantifiers reasonably well, the modal auxiliaries, for example, seem to disregard SOC altogether. Modal adverbials, on the other hand, are clearly sensitive to SOC. In a semantic composition and translation theory such a discrepancy would be an idiosyncrasy which, technically speaking, can be captured by the formulation of some special provision that would hopefully do sufficient justice to the observed facts. But the description and the analysis would inevitably remain what is commonly called ad hoc. In the syntactic lowering analysis, on the other hand, the fact that, for example, the modal auxiliaries seem insensitive to 
SOC can be reduced to the independently established feature of these verbs that they are not lowered into their argument-S but induce some form of raising (subject raising or predicate raising, according to the language in question). By stipulating that SOC applies only to lowered elements the apparently exceptional status of the modal auxiliary verbs is automatically accounted for, without any loss in generalization. Let us look at some details.

In order to demonstrate this point we shall not use English examples, mainly because English is not very informative on this score, due, in part, to the fact that English has the peculiarity that any higher not lowered upon the modal auxiliary verb may (i.e. in the meaning 'not possible') changes the auxiliary complex into cannot or can't, so that may not can only have meanings with the negation following the possibility operator and cannot can only have meanings with the operators in question inversely ordered. A better language to demonstrate this point is German (or Dutch), where no such morphophonemic alternation exists. Note that, in German as well as in Dutch, the modal auxiliary verbs induce predicate raising, not subject raising, as appears from the infinitival strings typical for these languages in cases where English has past participles plus lower VPs. ${ }^{9}$

Consider the following German sentence:

a. Luise kann zwei Bücher nicht gelesen haben. (Luise may/can two books not read have)

In terms of RQT with negation and modalities, this sentence can have the readings $(27 \mathrm{~b}-\mathrm{d})$ but not those in $(27 \mathrm{e}-\mathrm{g})$ - where Poss stands for the epistemic possibility operator:

(27) b. Poss $-\exists 2 \mathrm{x}$ : Book - not [Luise have read $\mathrm{x}$ ]

c. $\quad \exists 2 \mathrm{x}$ : Book - not - Poss [Luise have read $\mathrm{x}$ ]

d. $\exists 2 \mathrm{x}$ : Book - Poss - not [Luise have read $\mathrm{x}$ ]

e. !Poss - not $-\exists 2 x$ : Book [Luise have read $x$ ]

f. !not - Poss - $32 \mathrm{x}$ : Book [Luise have read $\mathrm{x}$ ]

g. !not - $\exists 2 \mathrm{x}$ : Book - Poss [Luise have read $\mathrm{x}$ ]

Two facts need comment at this point. First, the readings that are excluded for (27a) are precisely those where the negation precedes the existential quantifier. Second, there seems to be no particular preferential reading for (27a): all three of (27b-d) seem equally appropriate no matter what intonational pattern is assigned to (27a). These two facts fit in quite well with the hypothesis that the negation and the quantifiers are sensitive to SOC but not the possibility operator when manifested as the modal auxiliary verb können. This hypothesis is reinforced by the observation 
that

(27) h. Luise kann keine zwei Bücher gelesen haben. (Luise may/can no two books read have)

can have precisely the readings $(27 \mathrm{e}-\mathrm{g})$ and cannot have the readings (27b-d). Moreover, when Poss is not manifested by a modal auxiliary verb (können) but by a modal adverb (vielleicht, i.e. 'perhaps', 'maybe'), which is subject to lowering, then suddenly SOC applies in full force to all three operators:

(27) i. Vielleicht hat Luise zwei Bücher nicht gelesen. (perhaps has Luise two books not read)

j. Luise hat vielleicht zwei Bücher nicht gelesen.

These two sentences are largely synonymous, and in terms of the analyses $(27 \mathrm{~b}-\mathrm{g})$, i.e. in terms of RQT with negation and modalities, their only possible readings are $(27 \mathrm{~b})$ and $(27 \mathrm{~d})$, whereby the former is clearly the primary (unmarked) reading and the latter requires a special accent on the quantifier zwei Bücher. Note that (27b) strictly follows SOC, whereas in (27d) the existential quantifier has been given scope over Poss, an irregularity which is clearly bound up with the special intonational feature required. A further possible combination is

(27) k. Luise hat zwei Bücher vielleicht nicht gelesen.

which seems to allow only for the reading (27d). (Special intonation on the existentially quantified NP zwei Bücher will be of no avail since it already occurs in leftmost position as far as those elements are concerned that are factorized out.) And the intonational escape clause appears not to work for vielleicht. The combination with vielleicht at the far right, as in

(27) 1. Luise hat zwei Bücher nicht vielleicht gelesen.

runs into the special difficulty that vielleicht, like its English counterpart perhaps, is a positive polarity item, so that it will not stand in the scope of negation unless the whole sentence carries an echo effect. In such cases the negation, which must be accented and must have the lexical form nicht (not, e.g., keine) invariably takes scope over all the other operators. ${ }^{10}$ (271) is, therefore, not a suitable case for testing SOC.

What follows clearly from the discussion and the analysis of the sentences $(27 \mathrm{a}, \mathrm{h}, \mathrm{i}, \mathrm{j}, \mathrm{k})$ is that the negation, the existential quantifier, and the modal adverbial vielleicht are all sensitive to SOC, whereas the modal auxiliary verb können is not. True, the elements that are sensitive to SOC are so in differing degrees. The existential quantifier, in particular, turns out to be more flexible than the others in that special accent can 
sometimes make it correspond to a semantic analysis where it has largest scope ${ }^{11}$ But the behavior, in this respect, of these operators is crucially different from the total license that seems to be granted to the modal verbs, which do not seem to be affected by SOC at all. In the lowering analysis this is no coincidence, since it has been established on independent grounds that the modal auxiliary verbs are not lowered but take predicate raising, attracting the lower verb, plus its arguments, into their own S.

The modal verbs behave, in this respect, precisely like other surface verbs that have scope, in the sense that they allow for operators over their own $\mathrm{S}$ as well as in a lower $\mathrm{S}$ constituting an argument to the verb in question. A verb like believe or expect (but not the factive verbs other than know, about which more below) has scope in the sense that it provides the space for semantic analyses figuring operators 'above' as well as 'underneath' it. A sentence like

$$
\text { a. Luise expects few people to turn up. }
$$

has at least the following two readings:

$$
\begin{aligned}
& \text { b. }[\operatorname{expect}(\text { Luise, }[\exists \text { few } \mathrm{x} \text { : People [will turn up (x)]])] } \\
& \text { c. [ }[\text { few } \mathrm{x} \text { : People [expect (Luise, [will turn up (x)])]] }
\end{aligned}
$$

(where the square brackets are labeled $S$ and the round brackets indicate arguments). That is, the verb expect can be said to take large scope in (28b) and small scope in (28c). Yet, although this verb takes scope, it is not sensitive to SOC, the reason being that it is not subject to lowering.

It seems to be a general feature of grammars, judging by the material considered in the few European languages studied from this point of view, that lexical predicates in semantic analysis are never lowered to become verb forms. If a scope-bearing lexical predicate manifests itself as a verb form, it is never lowered. (The condition that the semantic predicate must be 'lexical' is added on account of finite verb forms like has or is marking tense, mood, or aspect; it seems useful to let these be generated via some form of lowering. ${ }^{12}$ They are, however, not 'lexical' in the sense that their lexical form in surface structure must be taken to be present at the level of semantic analysis. One indication for this is the fact that the simple past tense in English lacks the auxiliary have in finite verb forms but is expressed by means of have (plus past participle) in infinitivals: she may have started the engine is ambiguous between 'possibly she has started the engine' and 'possibly she started the engine'. The use of have in these cases cannot be part of semantic analysis, or, in other words, it appears that tense, aspect, and mood are expressed by means of abstract predicates in semantic analysis, and not by means of whatever surface verbs may 
manifest these categories.) This means that, for example, the epistemic modals, as well as lexical verbs such as believe or expect, cannot be subject to lowering and cannot, therefore, be sensitive to SOC.

The fact that only (lexical) lowering predicates, and not other possible candidates for the factorizing out typical for quantifiers and negation, are sensitive to SOC speaks out in favor of a syntactic treatment of the phenomena in question, and against the composition and translation approach. The reason is that in the latter no distinction is made between lowering and other syntactic forms of mapping factorized onto unfactorized ('integrated') structures and vice versa, so that no principled account is given in that approach of the differences that correspond with the different mapping methods. It cannot be claimed that the composition and translation method is in principle unable to build in provisions that will get the facts right. It would seem, on the contrary, that such provisions can very well be built in. The point is, however, that they will fail to capture the fact that the distinctions needed are already known on independent grounds from ordinary syntax.

\subsection{Syntactic islands}

The same point can be made, with greater force, on grounds of scope restrictions that correspond with well-known syntactic islands. Syntactic islands are structures, usually sentential structures, which do not allow for movement of material into or out of them. In English, adverbial clauses, dependent questions, relative clauses and generally clauses within a complex NP, and single conjuncts of sentential conjunctions are syntactic islands. (Languages differ as to what syntactic islands there are to be found in them, yet they do not differ arbitrarily. On the contrary, in spite of the differences there are nontrivial similarities, but what the universal constraints are that are operative here is simply not known at the present moment.)

Adverbial clauses are mostly introduced by a subordinating conjunction (since, when, because, if, etc.). There is no rule in English syntax permitting movement of material into or out of such clauses, either cyclically or postcyclically. All forms of raising or lowering are restricted to nonadverbial clauses, and the same applies to such postcyclic rules as $\mathrm{WH}$-fronting or other forms of fronting. Thus the following are ungrammatical: ${ }^{13}$

a. *Who are you angry because Harry deceived?

b. *I never met the person who you are angry because Harry deceived. 
c. *That poor girl I got angry when Harry deceived.

Likewise, quantifiers occurring in adverbial clauses are interpretable only as operating over the clauses in question, not over the whole sentence. Thus, (30a) is interpretable as (30b) but not as $(30 \mathrm{c}):{ }^{14}$

(30) a. She got angry because Harry was talking with some woman.

b. She got angry because $\exists \mathrm{x}$ : Woman [Harry was talking with $\mathrm{x}$ ]

c. $\exists \mathrm{x}$ : Woman [she got angry because Harry was talking with $\mathrm{x}$ ]

The same parallelism is observed in dependent questions:

a. *What did she ask if Harry had bought?

b. She asked if Harry had bought some gadget.

Just as (31a) is ungrammatical, (31b) can only mean 'she asked if there was a gadget that Harry had bought', and not 'there is/was a gadget such that she asked if Harry had bought it'.

Ross (1967) introduced into linguistics the notion of complex $N P$, i.e. an NP with a lexical head and incorporating a clause. He formulated the famous complex NP constraint, which stipulates that no material is ever moved into or out of an S within a complex NP. This constraint has proved highly resistant to counterexamples (though perhaps not entirely). It is anyhow valid for English and most other European languages without exception. There are two main categories of complex NP: those whose head is a content noun (the idea that, the rumour that, etc.), and those with a lexical antecedent as head and a relative clause as embedded S. Both clearly fall under the complex NP constraint, and both clearly limit quantifier scope to the embedded $\mathrm{S}$ :
a. *Who are you surprised at the rumor that Jack will tackle?
b. She was surprised at the rumor that Jack would tackle every opponent.

Just as (32a) is ungrammatical on account of movement of WH-material out of the S embedded in a complex NP, (32b) can only mean 'she was surprised at the rumor that for every opponent $\mathrm{x}$ Jack would tackle $\mathrm{x}$ ', and does not have a reading with the universal quantifier over the whole sentence. Likewise with relative clauses: ${ }^{15}$

a. *The difficult problem I was impressed by the girl who solved.

b. I was impressed by the girl who knew every answer.

Just as (33a) is ungrammatical on account of fronting of material out of a relative clause, $(33 \mathrm{~b})$ is interpretable only with the quantifier every answer staying within the relative clause. 
An interesting illustration of this constraint is provided by factive predicates. ${ }^{16}$ All factive predicates, except know, allow for an expansion of the that clause in terms of the fact that:

(34) a. Joan realized (the fact) that she stood little chance of winning.

b. It's a shame (the fact) that she was treated with such contempt.

c. I know (*the fact) that you want to make money out of me.

It is well known (Kiparsky and Kiparsky 1971) that factive verbs (except know) never allow for subject raising out of the embedded factive clause:

a. Old Salvatore *regretted $/{ }^{*}$ realized $/{ }^{*}$ gave away $/$ knew his sons to have gone into organized charity.

b. Old Salvatore regretted/realized/gave away/knew that his sons had gone into organized charity.

In fact, no cyclic rule is allowed to move material into or out of factive that clauses (except those with know). Thus, no factive adjective allows for the treatment known as tough movement:

This man is easy $/{ }^{*}$ regrettable to tease.

Postcyclic movement rules, however, operate freely on factive that clauses:

(37) a. Who does she regret that her husband gave the sack?

b. I've never met the man that Salvatore realizes will let him down.

c. Luciano Salvatore regrets he can't trust.

These observations are accounted for by the hypothesis that factive clauses (except those with know) are of the form the fact that in deep structure and are thus part of a complex NP so that no movement of material into or out of them is possible. At the end of the cycle, however, there is optional fact deletion: when this rule is applied the factive that clauses are no longer part of a complex NP and movement rules can operate freely. The verb know may be seen as incorporating the head noun fact lexically, so that it does not turn up in deep structure. This leaves that clauses under know unaffected by the complex NP constraint.

If this hypothesis is correct it follows that quantifiers in factive that clauses, except those with know, can operate only over the clauses in question and not over the whole sentence. Unfortunately, this is not easy to test, since the truth of factive clauses is presupposed, which implies (see Seuren 1985: ch. 3) that the factive clause is interpreted as immediately preceding the sentence containing it. Thus, (34a) is interpreted as 'Joan stood little chance of winning, and she realized that'. This means that 
quantifiers in factive clauses are interpreted as operating over sentences preceding the sentence to be processed, which leads to a blurring of scope distinctions in sentences containing quantified factive clauses. Thus, intuition does not seem to tell us unambiguously that, for example, in (38a) someone takes scope over the that clause only, whereas in (38b) it may also take scope over the whole sentence:

(38) a. She realizes that someone is going to help her.

b. She knows that someone is going to help her.

There are, however, other means of testing the consequences of this hypothesis for operator scope in factive clauses. As is well known, all verbs taking embedded Ss as possible arguments in subject position as well as in object position (mean, prove, suggest, etc.) are factive with respect to the subject clause (see note 16 above):

(39) (The fact) that the man was staggering suggested that he had been drinking.

It is generally so that quantifiers taking scope over a whole sentence can bind variable pronouns in subordinate clauses. These pronouns are obligatorily pronominal and cannot be replaced, salva veritate, by, for example, pronominal epithets (see Seuren 1985: section 4.2). Thus, (40a) and (40b) allow for the same person to be referred to by, respectively, he and the old crook, but the binding of the variable pronoun in (41a) cannot be paralleled by (4lb):

(40) a. Nobody laughed - because he was angry.

b. Nobody laughed - because the old crook was angry.

(41) a. Nobody laughed because he was amused.

b. Nobody laughed because the old crook was amused.

If we now insert a quantifier in the factive subject clause of a bisentential verb, and try out whether this quantifier can bind a variable pronoun in the object clause, we see quite clearly that it cannot do so:

(42) a. (The fact) that everyone was staggering suggested that he had been drinking.

b. (The fact) that everyone was staggering suggested that they had been drinking.

c. (The fact) that everyone was staggering suggested that the idiots had been drinking.

d. (The fact) that someone was staggering suggested that he had been drinking.

e. (The fact) that someone was staggering suggested that the idiot had been drinking. 
Sentence (42a) is not interpretable on a reading whereby everyone binds he. If everyone could take scope over the whole sentence, then it should be able to bind $h e$. The fact that it cannot strongly supports the claim that it cannot take scope over the whole sentence. In (42b) the pronoun they takes up everyone. This, however, is not binding of a variable pronoun by a quantifier; the pronoun they is a denoting pronoun, not a bound variable pronoun, as appears from the possibility of (42c), where the epithet the idiots replaces they, salva veritate. Likewise in (42d), where the pronoun he might be taken as being bound by someone. The possible substitution by the idiot in (42e), however, shows that the he in (42d) is a denoting pronoun, not a bound variable pronoun. The denoting function of the pronouns or epithets in question is best illustrated by the interpretation for factive clauses mentioned earlier. On this analysis, (42b-e) are analyzed or interpreted as, respectively,

(42) $b^{\prime}$. Everyone was staggering, and this (fact) suggested that they had been drinking.

$\mathrm{c}^{\prime}$. Everyone was staggering, and this (fact) suggested that the idiots had been drinking.

$d^{\prime}$. Someone was staggering, and this (fact) suggested that he had been drinking.

$\mathrm{e}^{\prime}$. Someone was staggering, and this (fact) suggested that the idiot had been drinking.

The apparent complications brought about by factive verbs in the context of quantifier lowering thus confirm, on closer analysis, the lowering hypothesis, rather than weakening it.

Single conjuncts of sentential conjunctions are likewise syntactic islands, and, likewise, quantifiers can only bind variables in such islands when they are part of the islands, not from further away. The island status of conjuncts was first discovered by Ross (1967), who proposed the coordinate structure constraint, forbidding movement into or out of single conjuncts:
a. *This is what John smokes cigars and.
b. *The cigars that John smokes pipe and are very expensive.
c. *Cigars John smokes pipe and.

These purely syntactic observations are matched by the semantic fact that quantification in one of two conjuncts is limited to that conjunct. Thus, (44a) can only have the reading (44b), not (44c), and likewise for (45):

(44) a. John drinks wine and something stronger.

b. John drinks wine and $\exists x$ : Stronger [John drinks $\mathrm{x}$ ] 
c. $\exists \mathrm{x}$ : Stronger [John drinks wine and John drinks $\mathrm{x}$ ]

a. Archie asked for beer and someone gave it to him.

b. Archie asked for beer and $\exists x$ : Person [ $x$ gave it to him]

c. $\exists x$ : Person [Archie asked for beer and $x$ gave it to him]

Logicians will say that there is no difference between (45b) and (45c), which is correct from a purely logical point of view. However, when possible deep structures, underlying surface sentences as semantic analyses, are considered, it is immediately clear that $(45 \mathrm{c})$ is not a possible reading for (45a), nor (44c) for (44a). It must be remembered that naturallanguage conjunction is not symmetrical the way logical conjunction is: the order of the conjuncts is often semantically relevant in that the second conjunct is interpreted in a domain where the first conjunct has already been asserted. (44c) shows that an existential quantification over the whole conjoined sentence is semantically incoherent: there is no way in (44c) to ensure that the comparative stronger is interpreted as taking wine as the comparee phrase. In (44b) this interpretation is induced by the fact that wine occurs in the first conjunct, and by the fact that deletion of comparee phrases is possible under conditions of external anaphora.

Again there is a complication. Whereas the syntactic coordinate structure constraint applies to all forms of conjunction, the corresponding scope constraint applies only to full sentential conjunction, i.e. to cases where the conjunction either consists of two full conjoined Ss or can be transformationally reduced, salva veritate, to full S-conjunction. The scope constraint does not, apparently, apply to what we may call reciprocal conjunction (known under a variety of names, such as NP conjunction, symmetrical conjunction), as in

(46) a. Nellie and Gerald are a nice couple.

b. Nellie and Gerald met in a railway compartment.

Such sentences are clearly not reducible to, respectively,

$a^{\prime}$. Nellie is a nice couple and Gerald is a nice couple.

$\mathrm{b}^{\prime}$. *Nellie met in a railway compartment and Gerald met in a railway compartment.

The grammatical analysis and description of reciprocal conjunction is still very much of a problem. In any case, whereas the syntactic coordinate structure constraint applies in full force to reciprocal conjunctions, the scope constraint does not, as appears from

(47) a. Nellie and some boy from the village were flirting with each other.

b. ?*Nellie and every boy from the village were flirting with each other. 
The former sentence is clearly fully grammatical and is interpreted with someone taking scope over the whole sentence: 'there is a boy from the village such that Nellie and he were flirting with each other'. Sentence (47b) seems more problematic in that the reading required, i.e. 'for every boy from the village it is so that Nellie and he were flirting with each other', is either impossible or hard to get. What lies behind these phenomena is impossible to say, given the present state of theoretical grammar. But it must be kept in mind that reciprocal conjunction is anyway still largely an opaque category.

\subsection{Conjunction reduction and lowering}

The question of conjunction reduction in grammar is a vexed one. A multiplicity of theories attempting to account for the complex and varied facts of conjunction in natural language has sprung up since the inception of transformational grammar. Most of these theories accept some form of conjunction reduction, and if there is anything like a standard opinion on the matter, it is that there are three distinct forms of conjunction reduction, i.e. standard conjunction reduction (SCR), right-node raising (RNR), and gapping. SCR occurs typically when two conjoined Ss differ in just one constituent, as in (48a). RNR occurs typically when two conjoined Ss are identical only as regards the last constituent as in (48b). Gapping is typical when two conjoined Ss differ in peripheral constituents but are identical in the central constituent, which must contain the verb, as in (48c):

(48) a. SCR: Harry saw the letter and Jim saw the letter $\Rightarrow$ Harry and Jim saw the letter

b. RNR: Harry wrote the letter and Jim saw the letter $\Rightarrow$ Harry wrote and Jim saw the letter

c. Gapping: Harry saw the letter and Jim saw the envelope $\Rightarrow$ Harry saw the letter and Jim the envelope

Apart from these three forms of conjunction reduction standardly found in the literature, there are the cases of reciprocal conjunction, which are treated in various ways or not treated at all.

Van Oirsouw $(1980,1984)$ attempts to unify the different forms of sentential conjunction (i.e. the cases where expansion to full conjoined Ss is possible) in one complex rule of deletion under conjunction. Seuren (1985) works with two forms of sentential conjunction reduction, i.e. cyclic conjunction reduction mapping (CRM), incorporating both SCR and RNR, and postcyclic gapping (cf. note 1). CRM consists in mapping 
the two conjoined Ss onto each other, whereby the constituents where the differences are found are united under a higher node and the differing constituents are juxtaposed, in the original order, with an empty slot between them to be filled by the conjunctor and. This conjunctor originates as a higher abstract binary predicate taking two Ss as arguments. After CRM only one $\mathrm{S}$ remains, with an empty slot for and to be lowered onto. The process is illustrated in $(13 a, b)$ above. We shall be concerned here with CRM only, not with gapping.

One reason for caution with regard to Van Oirsouw's far-reaching proposal is the fact that there is a curious interplay between conjunction reduction and existential quantification, not accounted for by Van Oirsouw's analysis. (More curious than the linguistic facts is the academic fact that the phenomena in question are rarely mentioned in the linguistic literature and never looked at carefully; in the formal semantic literature the phenomena in question seem to have passed totally unobserved.) The interplay can be observed when existential quantification and sentential conjunction reduction co-occur in one sentence, as in those of (49). It is then noticed that in some cases the deletion involved in conjunction reduction involves a second quantifier of identical form, so that the sentence is interpretable with double existential quantification, whereas in other cases the deletion must have been such that only one quantifier is involved. Cases of double quantification (as either the only possible or at least the preferred reading) are marked with ' 2 '; cases with exclusively single quantification are marked with ' 1 '. (Note that analogous phenomena for the universal quantifier are beyond observation, given the fact that no truth-conditional difference arises whether single or double quantification is involved.) Now consider:

(49) a. Some burglar stole both the TV set and the necklace. (1)

b. Both the TV set and the necklace were stolen by some burglar. (2)

c. Someone must have both sprayed and repaired that car.

d. That car must have been both sprayed and repaired by someone.

e. Often Harry eats both fish and meat.

f. Harry eats both fish and meat often.

g. Lisa bought and sold something.

h. Lisa bought and Harriet sold something.

i. Lisa and Harriet bought something.

j. Tony killed someone for money and Hank for fun.

What is remarkable about these sentences is that whenever the existential (some, or often) precedes and, there is single quantification, and whenever 
it follows and, there is multiple quantification, except in (49j). But (49j) is the only case of gapping; (49a-i) are all cases of CRM, where conjunction reduction has taken place in the cycle and the lowering of and is, apparently, subject to SOC. SOC is not operative for (49j) because there the reduction has taken place in the postcycle.

Schematically, (49a) is considered to have the following deep structure:

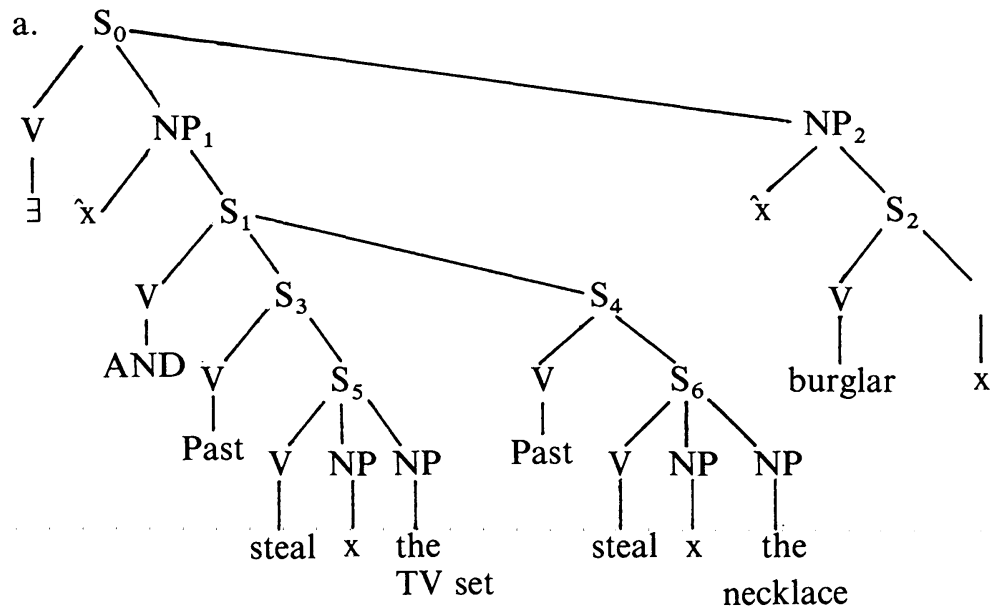

After CRM on the $\mathrm{S}_{1}$ cycle, including tense processing as sketched in note 2 , and after application of the treatment reserved for quantifiers as shown in $(14 a-c)$, the result is

(50) b.

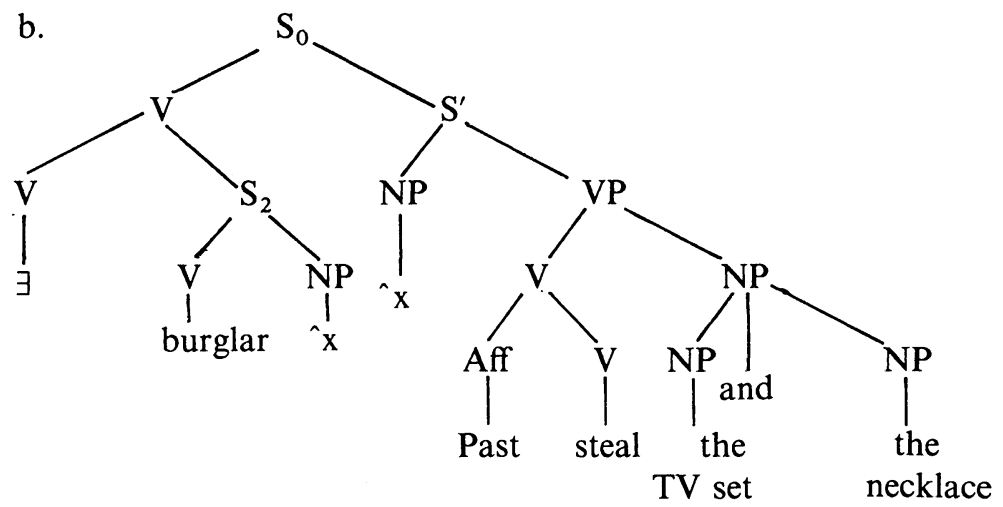

Now, on the $S_{0}$ cycle, the complex $V$, i.e. the quantifier, can be lowered safely into $S^{\prime}$, since the landing site of the quantifier is the position occupied by the bound variable $x$, and this position remains to the left of the operator and lowered earlier. 
If the deep structure of (49a) had been

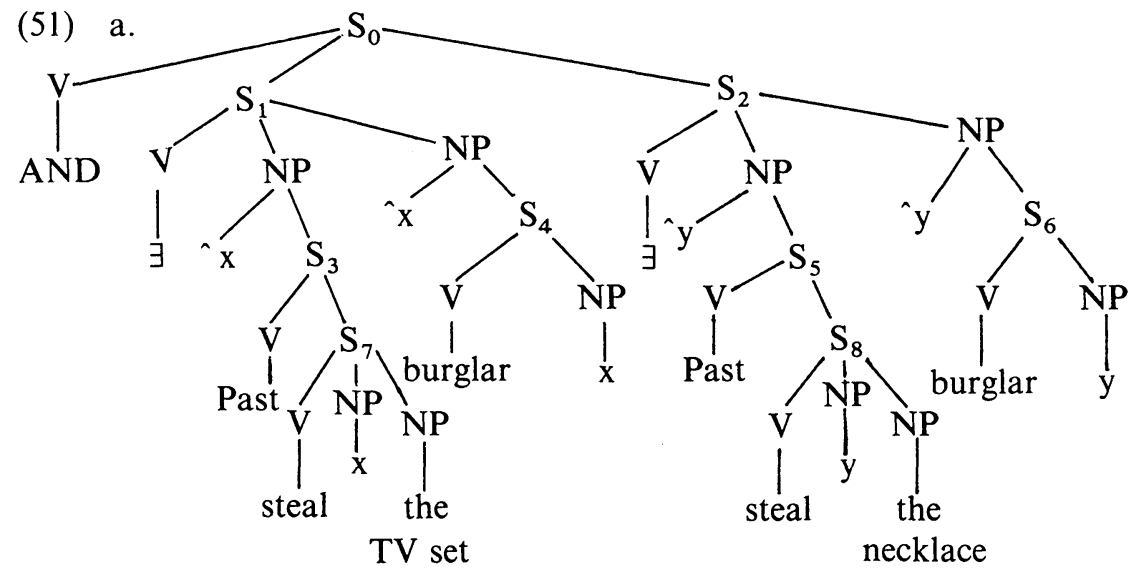

then, after tense processing and quantifier lowering on both $S_{1}$ and $S_{2}$, the result would have been
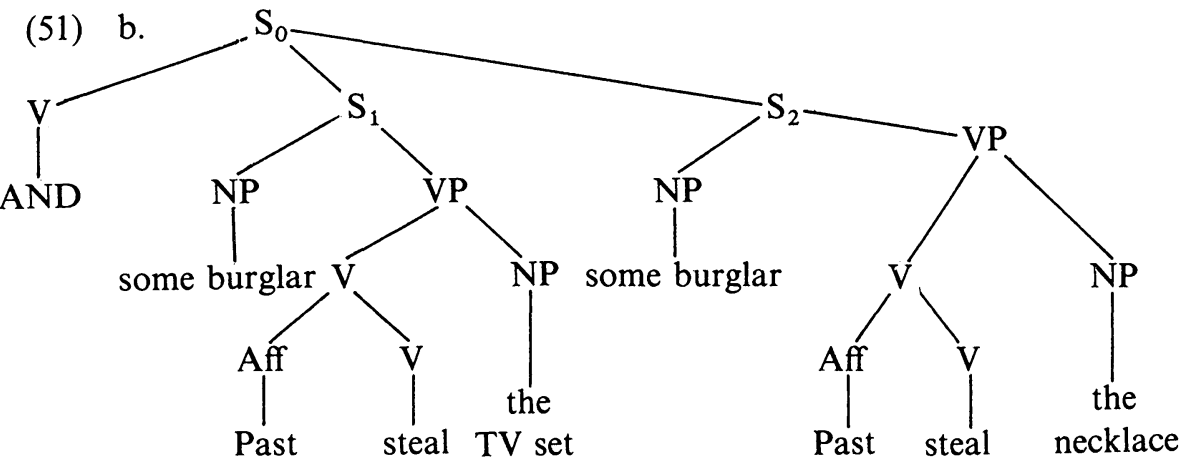

Cyclic CRM on $\mathrm{S}_{0}$ yields

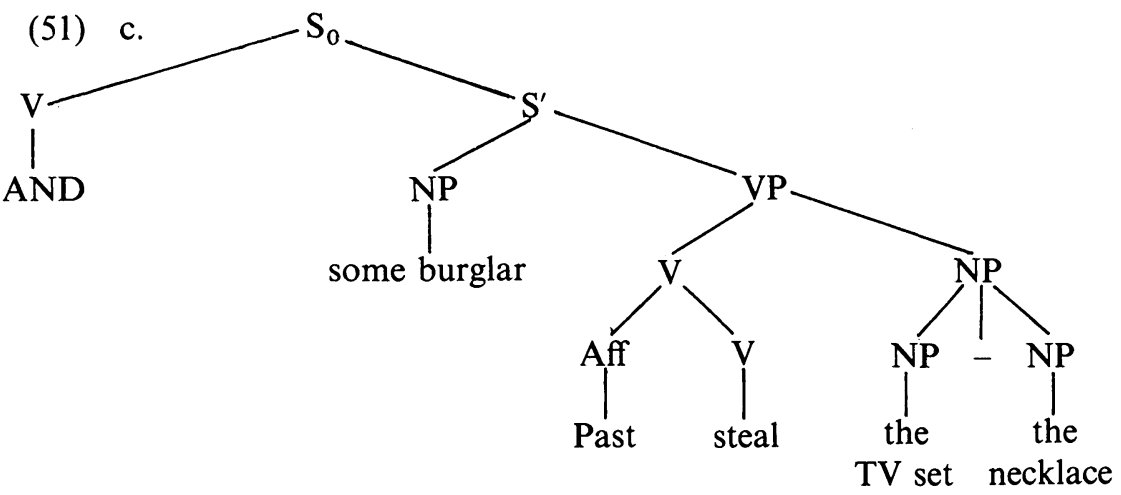


Now AND must be lowered to the position indicated by '-'. However, since (49a) cannot have the reading represented by (51a), this lowering must somehow be blocked. SOC seems the best candidate for this blocking, but how exactly does this work? (51a) can, of course, be converted into a proper surface structure:

(49) k. Some burglar stole the TV set and some burglar stole the necklace.

This shows that the theory must allow for lowering of AND in a structure like

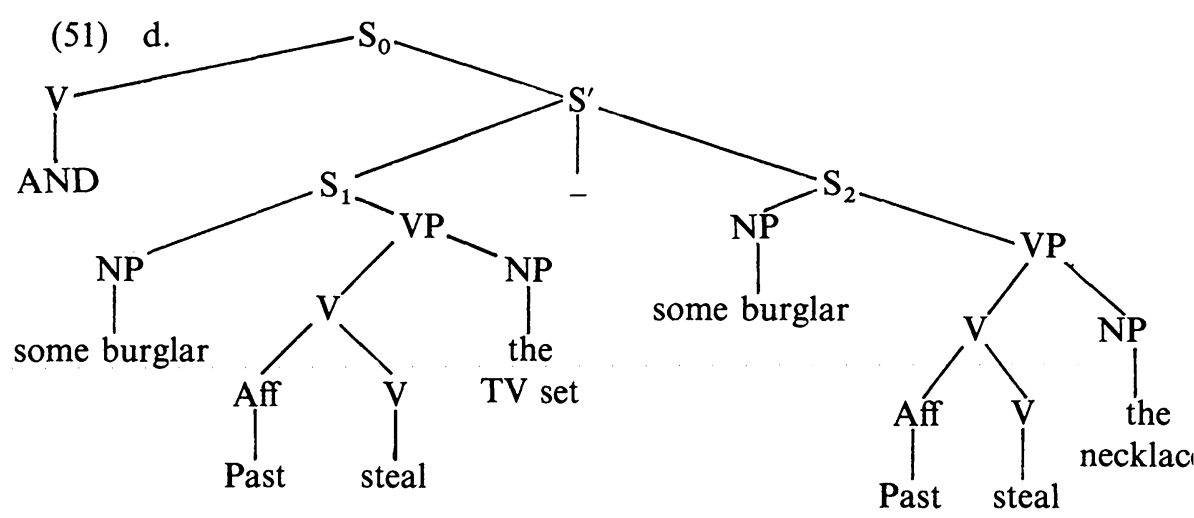

where AND will land as and in the position indicated by '-'. Obligatory CRM has been applied in the laxest possible manner: the whole of both Ss has been taken as nonidentical (cf. sentence [iv] in note 1). It is clear that the crucial difference with (51c), where CRM has been applied in the strictest possible manner, i.e. minimizing the nonidentical constituents, consists in the fact that in (51c) the constituent some burglar represents two original NPs some burglar collapsed into one NP by CRM, whereas in (51d) the two original NPs some burglar are left intact. Apparently, therefore, SOC for AND allows AND to be lowered across a quantifier lowered earlier in $S_{1}$ but not across a quantifier (or its representative) lowered earlier in $\mathrm{S}_{2}$. Since some burglar in (51c) represents, besides the quantifier lowered in $S_{1}$, also the quantifier lowered in $S_{2}$, the lowering of AND is blocked in (51c) but not in (51d). One might say that, apparently, AND is subject to SOC only if CRM, triggered by AND, has affected some SOC operator lowered earlier.

On this analysis, all the observations made in (49) turn out to be regular. (50a) can underlie (49a) but not (49k). (51a) can underlie (49k) but not (49a). (51a), with $S_{7}$ and $S_{8}$ passivized, can underlie (49b). Instead 
of $(51 b)$ we then have

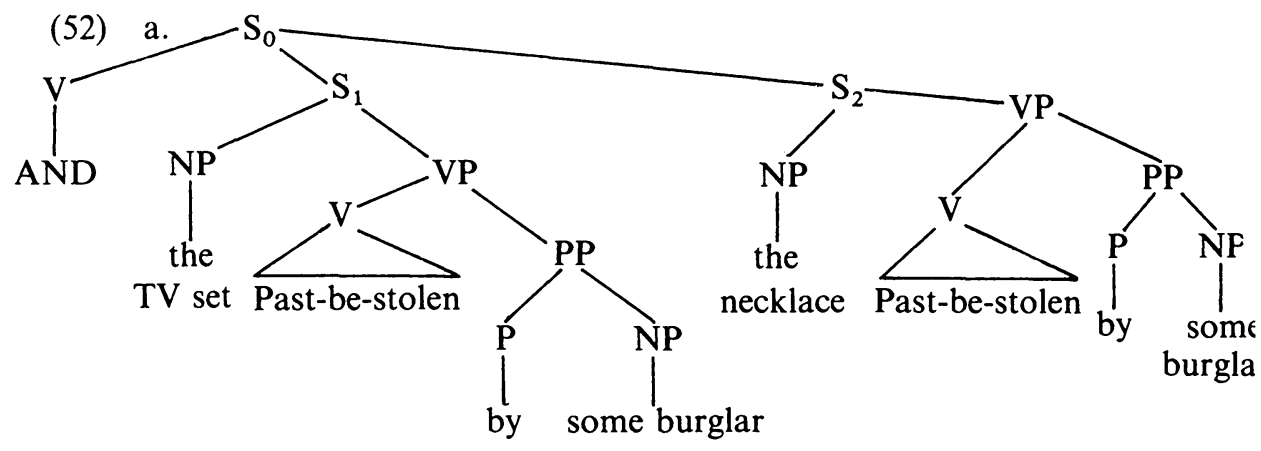

Minimized CRM yields

(52) b. AND [the TV set - the necklace Past-be-stolen by some burglar]

after which AND can be lowered without any SOC trouble, since its landing site safely precedes some. This gives us the primary reading of (49b).

It is also possible, however, to read (49b) in the sense of (50a), with $S_{5}$ and $S_{6}$ passivized - i.e. with single quantification over AND. For this reading to be realized it is necessary that the existential quantifier crosses over the lowered and:

(53) $\exists \mathrm{x}$ : Burglar [the TV set and the necklace Past-be-stolen by $\mathrm{x}$ ]

This derivation would violate SOC if SOC were an absolute constraint. But, as has been observed by many authors, some SOC operators can compensate for disturbed left-to-right order by special intonational features, and the existential quantifiers are prime cases of intonational compensation. In fact, $(49 \mathrm{~b})$ can only have the reading that corresponds with (53) if the NP some burglar is placed under a rising intonation and not the normal sentence-final falling intonation. The propositional operators and, or, not do not have this possibility: it is never possible for these operators to cross over previously lowered operators and compensate for that by intonational features. If that were possible then (51a) would be a possible, though secondary, semantic source for (49a), which it is not. Moreover, with all lowering operators allowing for such compensation the lowering analysis would lose much of its force. Its only empirical support would then come from intonational features, and such a basis would be flimsy, given the manifold ambiguities associated with intonational features. In actual fact, however, the specific behavior of the 
various SOC-sensitive operators, and in particular the specific ways in which and the extents to which they conform to SOC, are a fruitful source for a better insight into the facts, and one hopes also the nature, of natural language and the species whose natural property it is.

The sentences $(49 \mathrm{c}-\mathrm{i})$ are now quite perspicuous. The same principles apply to all of them. (49j), however, falls outside this system: it is the only sentence where a multiple quantification reading is possible although the existential precedes and. As has been said, however, (49j) is an instance of postcyclic gapping. As is easily checked, minimal CRM requires multiple and and the addition of respectively, as shown in note 1. CRM is most naturally applied here in the maximal sense: the whole of both Ss is considered different and thus linked up with a lowered and. At the end of the cycle, (49j) has the structure

(54) Tony killed someone for money and Hank killed someone for fun.

with double quantification. Gapping now allows for the identical part killed someone to be deleted from the second conjunct, without any change or loss of meaning. A single quantification reading is ruled out for (49j) since it is clearly a case of gapping and thus requires (54) as the endcyclic ('shallow') structure, and (54) has the double quantification in explicit form.

It thus looks as though the grammatical and semantic facts of conjunction reduction and quantification fit together in one coherent grammatical system mapping semantic analyses onto surface structures and vice versa. This system crucially involves lowering as well as a duly relativized SOC.

\subsection{Negative raising}

The lowering analysis is, surprisingly, confirmed by phenomena that are analyzable in terms of the raising, not the lowering, of a typical SOC operator, the negation (the minimal one, that is). It has been observed for many centuries that a sentence like

a. I don't think you are right.

does not mean 'it is not the case that you are right' but has a nontrivial similarity with 'I think that you are not right'. In fact, the traditional observation has usually been that (55a) means precisely what the latter analysis says, but this is clearly incorrect, a mistake that was perpetuated in modern theoretical grammar. When the rule of negative raising was proposed in theoretical grammar, in the context of transformational grammar in its happier days, it was uncritically assumed that (55a) has as 
its primary reading ' $I$ think that you are not right'. It was soon observed that this is not correct: the two are not synonymous, even though there may not be a difference in truth conditions. They clearly differ in conditions of use and in other, less clearly statable, semantic respects. (55a) is, for one thing, more like an explicit performative than its analog:

b. I think that you are not right.

It is more like 'I hereby express the thought that you are not right', whereas (55b) is no more than an assertion made by a speaker about what he thinks. These semantic discrepancies offered an opportunity to certain theoretical linguists, whose theories were not naturally compatible with the rule of negative raising (for reasons that, incidentally, have proved to be of passing interest only), to dismiss this rule as unfounded.

This conclusion, however, was not only unnecessary, it was also mistaken. There are too many indications that negative raising is indeed a rule of syntax for it to be dismissed in so facile a manner. Thus, as is pointed out in Seuren (1974), those negative polarity items that otherwise always require a negation or a negative expression to be present in the same clause also occur in cases of negative raising where the negation is in the higher clause:

(56) a. I don't think he has arrived yet.

b. I didn't think he would come back any more.

Note that when the higher clause contains a verb not inducing negative raising, the result is ungrammatical:

a. *She doesn't know he has arrived yet.

b. *I didn't hope he would come back any more.

(The latter sentence is grammatical only in the reading where any more is in construction with hope, but when any more is part of the subordinate clause the sentence is clearly out of bounds.) Many other facts can be adduced. Thus, for example, there is the fact that in Dutch it is not only the ordinary negation that can be raised this way but also the word nooit 'never': ${ }^{17}$

(58) Ik had nooit gedacht dat je nog zou komen.

I had never thought that you yet would come

'I hadn't thought you would still come'

There are a great many interlingual differences with regard to negative raising. In English for example, the verb hope does not induce negative raising, but its Dutch equivalent hopen, like the French espérer, does. (Italian sperare, again, does not.) That this is not just a question of 
semantics but also of syntax is shown by the ungrammaticality of the English sentence (59a) and the grammaticality of its Dutch and French counterpart $(59 \mathrm{~b}, \mathrm{c})$. Note that all three involve the negative polarity item any/enig/aucun:

a. *I don't hope that she has any idea of your plans.

b. Ik hoop niet dat ze enig idee heeft van je plannen. I hope not that she any idea has of your plans

c. Je n'espère pas qu'elle ait aucune idée de tes plans. I hope not that she has any idea of your plans

In a moment, more evidence will be adduced for the syntactic status of negative raising, based on an extrapolation from ordinary surface verbs inducing this rule to abstract predicates such as all, and, must (as in Seuren 1974). What counts here is that the semantic differences between the raised and the nonraised version of the sentences in question do not rule out negative raising as a rule of syntax. We can say that negative raising is obligatory and is induced by the very semantic features that distinguish raised from nonraised versions, with verbs that are lexically marked for this rule. This formulation saves both the rule and the semantics.

One typical fact of negative raising is that the semantic analogy between the raised and the nonraised version invariably holds only when the (minimal) negation is the highest operator of the subordinate clause. Thus, a sentence like (60a) is semantically analogous to (60b), and not to (60c); and likewise in $(61 \mathrm{a}-\mathrm{c})$ :

(60) a. I don't believe that many people will vote for him.

b. I believe that not many people will vote for him.

c. I believe that many people will not vote for him.

(61) a. I don't think everything has been said yet.

b. I think not everything has been said yet.

c. I think everything has not been said yet.

This fact is easily captured in the lowering analysis, which requires semantically underlying deep structures in terms of RQT. Schematically, the underlying structure of $(60 \mathrm{a})$ is

(62) a. Believe (I, [not [ $\exists$ many $x$ : People [vote (x, for him)]]])

After lowering of the existential many, the structure looks:

(62) b. Believe (I, [not [vote (many people, for him)]])

The next lowering should now affect not. However, believe being a negative-raising verb, this lowering is temporarily suspended. Then, on 
the next cycle up, controlled by believe, negative raising applies. The effect of this rule is that the negation just under believe is detached and reattached above believe under a newly created $S^{\prime}$ node:

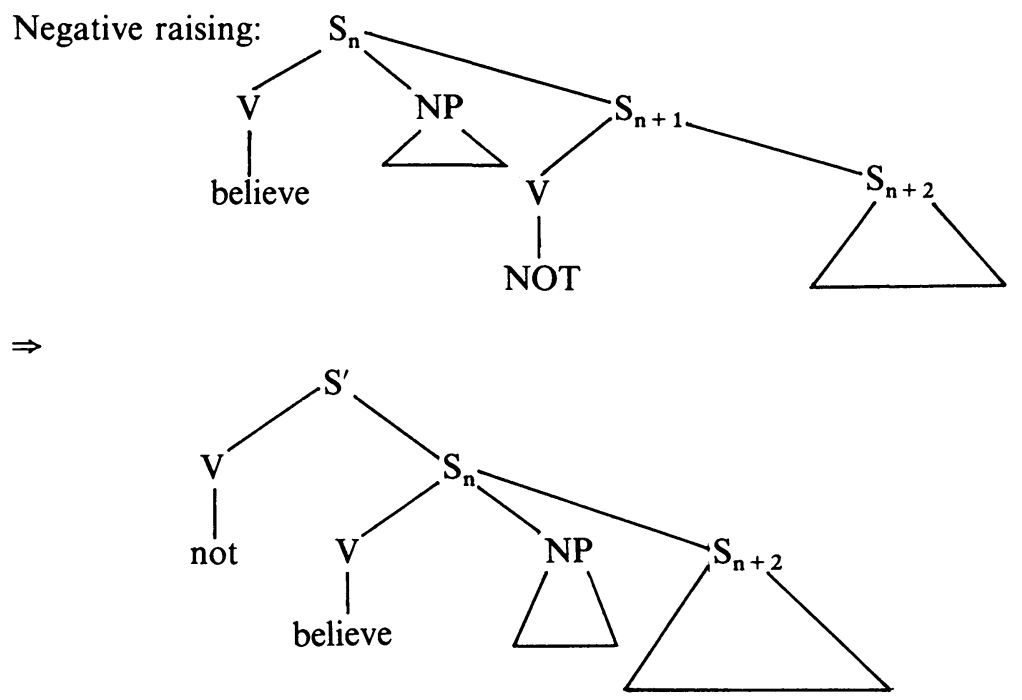

Then, on the $\mathrm{S}^{\prime}$ cycle, not is lowered - unless there is, again, a higher negative-raising predicate suspending the lowering.

So far, the analysis is confirmation for the lowering analysis for two reasons: first, the requirement that, at the moment negative raising is about to apply, not must be the highest predicate of the subordinate clause $\left(S_{n+1}\right)$ is expressible in a straightforward way in the analyses current in the lowering theory; and second, the mechanism of negative raising fits in naturally with the lowering machinery. The description and analysis gains considerably in explanatory power, however, and becomes considerably more resistant to awkward cases, when negative raising is considered a property of certain abstract predicates (which do not manifest themselves as verbs in surface structures). In other words, by extrapolating from fairly obvious cases to more abstract instances the description, and its concomitant analysis, show their true mettle.

The modal auxiliary must, especially its epistemic variety, appears to be a negative raiser. In standard English this raising has the effect of changing the lexical form of must into its logical counterpart can. The reason for this assumption is mainly that the semantic content of 'it is necessarily so that Jim is not ill' is not expressed naturally as (64a) but rather as (64b); (64c) can mean a variety of other things:

(64) a. Jim must not be ill. 
b. Jim can't be ill.

c. Jim mustn't be ill.

In certain varieties of colloquial English, however, the lexical switch from must to can does not take place, so that (64c) means precisely what (64b) says. This analysis is confirmed by French, where one finds normal colloquial sentences like

(65) Ça ne doit pas être gai là-bas.

meaning 'it can't be very nice over there' although it says literally 'it mustn't be very nice over there'. The positioning of the negative particles ne ... pas shows unambiguously that the negation is grammatically constructed, in surface structure, with the auxiliary doit 'must', and not with the lower infinitive être 'be'. For if it were constructed with the latter, the sentence would have been Ça doit ne pas être gai là-bas.

By the method of extrapolating from obvious cases to less visible and more abstract categories of grammar and the lexicon, we may assume that the same relation as between (55b) and (55a), or between (64a) and (64b), exists between sentences with the universal quantifier over a negation and their counterparts with the negation over the existential quantifier, as in (66a) and (66b), respectively. Or between sentences with cause over not and their counterparts with not over let, as in (67a) and (67b):

(66) a. Everybody did not laugh. (They were all too shocked.)

b. Nobody laughed. (They were all too shocked.)

(67) a. I caused him not to go.

b. I didn't let him go.

This implies that the predicates $\forall$ and cause are negative raisers, changing into their logical counterparts $\exists$ and let when negative raising is put into effect. $^{18}$

The same can be said of the abstract predicate AND, as can be seen from the pair

a. ?She doesn't like tea and coffee.

b. She doesn't like tea or coffee.

In full sentential form, (68b) means 'she doesn't like tea and she doesn't like coffee', or

a. AND [not [she likes tea], not [she likes coffee]]

After lowering of both negations, this would give

b. AND [[she not likes tea], [she not likes coffee]] 
CRM should now produce (in minimal application)

c. AND [she not likes tea - coffee]

after which AND should be lowered into the empty position. But, as has been shown, this it is not allowed to do due to SOC, since it would have to jump across not, which is the collapsed form of both negations. All that can be done after (69b) is a maximal application of CRM, yielding

d. AND [she not likes tea - she not likes coffee]

which will then become the surface structure: ${ }^{19}$

c. She doesn't like tea and she doesn't like coffee.

On the negative raising analysis, (68b) is derived as follows. The underlying

(70)

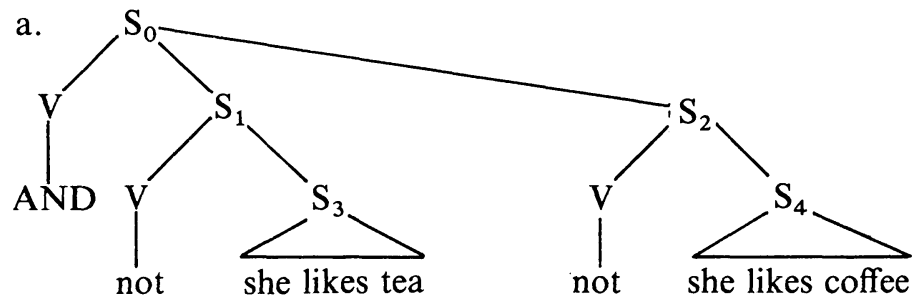

must allow for a derivation where the two negations are not lowered into their argument Ss, but where the collapsing of material under CRM on the $S_{0}$ cycle affects the negations as abstract predicates, not as lowered negative particles. Let AND be a negative raiser only when it stands over one single not, which is a predicate (V), collapsed from two original negations under CRM, and when it is left with one single (collapsed) $\mathrm{S}$ argument:

(70) b.

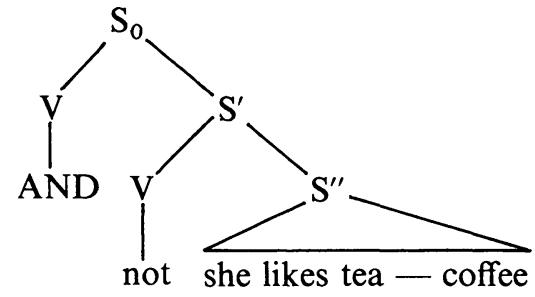

This requires of the grammar that the lowering of not is suspended not only in (70b) but also in (70a), if that lowering is to be followed by the collapsing, under CRM, of the two negations. Or, in other words, the cycles $S_{1}$ and $S_{2}$ are suspended in (70a) and the grammar moves on to $S_{0}$, provided the two negations are mapped onto a single not under CRM on 
the $S_{0}$ cycle, thus yielding (70b). (There is, of course, no problem in programing this into the routine procedure of the grammar.) Now negative raising applies, yielding

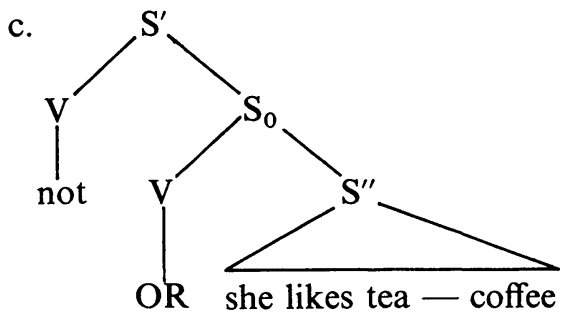

OR is now lowered into the empty position, and, on the next cycle up, not is lowered into its canonical position with the finite verb, thus yielding ((68b), without any violation of SOC.

This analysis is confirmed by the observation that a sentence like

(71) a. I don't think either Harry or Ted were late.

is perfectly grammatical even though the subordinate clause on its own is not:

b. *Either Harry or Ted were late.

Without going into the complex and vexed question of precisely how and when the feature PLURAL is assigned to finite verbs, we may reasonably surmise that the plural form were in (71a) finds its origin in an underlying AND, given the fact that in

c. Both Harry and Ted were late.

the plural is obligatory. Note, moreover, that the sentence

(71) d. I don't think either Harry or Ted was late.

is interpretable only in the nonraised meaning 'it is not the case that I think that either Harry or Ted was late'.

The overall conclusion is that negative raising requires a grammatical treatment involving raising for the observations of grammaticality and of possible readings to be accounted for properly, and that, at the same time, this grammatical treatment is not feasible without the concomitant procedure of lowering of certain operators. Thus raising and lowering are intertwined in transformational syntax, so that it is not possible to say that the one belongs to syntax but the other to semantics: both are seen to be part of syntax, or, in other words, both play their part in the mapping of deep semantic analyses onto surface structures and vice versa. 


\subsection{Accented constituent lowering}

So far, the argument has relied on similarities between constraints on known grammatical rules on the one hand and interpretative possibilities on the other; it has moreover been shown that the difference between those operators that do and those that do not obey SOC can be accounted for naturally by the assumption that the former are lowered and the latter are not; and finally it has become clear that the integration of lowering into an otherwise well-motivated syntactic machinery is indispensable for the machinery to work properly. It has not been shown, however, that lowering is a grammatical process needed independently in the grammar anyway. In this section it will be demonstrated that lowering is a process required anyway for the grammatical or syntactic description and analysis of contrastively or emphatically accented constituents.

As is well known, the grammatical difference between sentences like (72a), (72b), and (72c) is semantically irrelevant:

(72) a. Peter didn't drink the WINE, he drank the GIN.

b. It isn't the WINE that Peter drank, it's the GIN.

c. What Peter drank wasn't the WINE, he drank the GIN.

In these three sentences the NP constituents WINE and GIN are in semantic contrast and are accordingly accented; the first of each pair of sentences has a sharply rising intonation at the end, matched by a rise or fall in the intonation of the contrasted NP in the second sentence. Contrastive accent is to be distinguished from emphatic accent, where no contrast is involved:

(73) a. Peter didn't drink the WINE.

b. It's the WINE that Peter did not drink.

c. What Peter didn't drink was the WINE.

Here the same accent as observed in (72) on the salient constituent is found again, but there is no rising intonation at the end of the sentence. Semantically, the negation is part of the presupposition (there is something that Peter didn't drink). In (72) the presupposition is 'there is something that Peter drank', and the negation is part of what is asserted. Both contrastive and emphatic accent are accounted for by the lowering analysis. The difference is neutralized anyhow when no negation is used.

Besides the distinction between contrastive and emphatic cases, there is also a distinction between, let us say, direct cases and quoted cases. This distinction appears from the following sentences:

(74) a. Peter drank the WINE. 
b. Al's behavior is not CONstructive, it's DEstructive.

c. She didn't drink SOME wine, she drank ALL the wine.

(74a) is appropriate when it has been said that Peter drank something (the presupposition). The reply may then be 'Yes, he drank the WINE'. Such a reply provides the predicate wanted for a topic expression. However, (74b) is not appropriate in a discourse where it has been said that Al's behavior is 'something -structive'. The presupposition of (74b) is, rather, that a sentence has just been uttered 'Al's behavior is constructive', and the sentence asserts that that sentence is all right provided the con-is replaced by $d e-$. Likewise for (74c), which presupposes not that she drank something, but that it has just been said that she drank some wine. The sentence asserts that that utterance is all right provided the some is replaced by all the.

All these different cases are accounted for by essentially the same cyclic rule of accented constituent lowering (ACL), formulated schematically as (75a) or, simplified, (75b):

a.

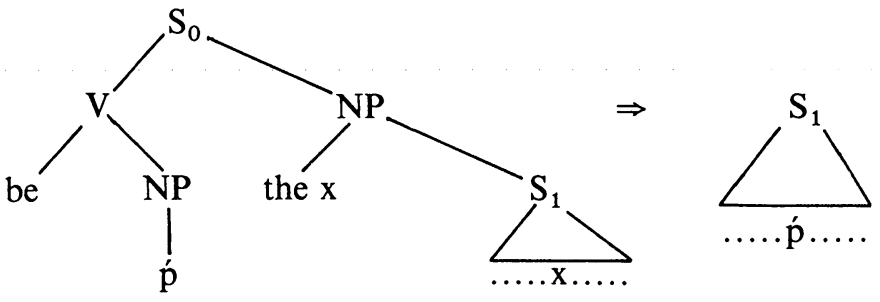

b. $\quad[$ be $\dot{p}($ the $x[\ldots . . . . .]).] \Rightarrow[\ldots . . \dot{p} \ldots .$.

where 'p' is the emphatically or contrastively accented constituent.

This rule is optional. It lowers the higher predicate 'p', which has the normal nuclear accent that goes with predicates, into $S_{1}$, whereby the higher predicate carries its accent with it. ACL must be applied when nonapplication would result in a violation of constraints upon the extraction and fronting of WH-constituents. Note that $S_{1}$ will become a relative clause if ACL is not applied. For relative clauses in English it is necessary that the relativized constituent is fronted as a WH-constituent. When such fronting is blocked, as in

(76) a. *It's CON that Al's behavior is structive.

b. *What Al's behavior is structive is CON.

c. *It's SOME that she drank wine.

d. *What she drank wine is SOME. 
ACL must be applied, with the results

(77) a. Al's behavior is CONstructive.

b. She drank SOME wine.

In all cases the accented element is represented as an NP: either because what is contrasted or emphasized is 'directly' used as an NP, as in (72), (73), (74a), or because what is contrasted or emphasized is a quoted element ('con-', 'some'), and quoted elements are always NPs. The difference between direct and quoted cases is accounted for by different forms of $S_{1}$ : in direct cases $S_{1}$ is simply the result of the normal cyclic procedure in the grammar; in quoted cases $S_{1}$ is a quoted surface structure with some constituent replaced by ' $x$ '. (We shall not attempt to elaborate on this class of cases, mainly because no adequate 'grammar of quotes' is available.)

It has been denied that ACL is a rule of (cyclic) syntax. Instead, according to these critics, contrastive and emphatic accents are to be accounted for by a separate late rule in the phonology, driven by a topic-comment distinction associated with the sentence in question, which places heavy accent on whatever constituent serves as comment to the topic expression. Such a rule would probably be a viable alternative were it not that the quoted cases just discussed are not instances of a topic-comment discussion but have a very different presuppositional structure (and do not allow for either cleft or pseudocleft versions). It might in turn be proposed that the topic-comment distinction is not relevant for emphatic or contrastive accent, but that such accents may be placed on any constituent in the sentence. That proposal, however, falls foul of fatal counterexamples. There are cases where no contrastive accent can be placed on a constituent for the precise reason that the remainder of the sentence is not a possible topic expression. Consider, for example,
a. *I don't think HARRY has arrived yet, I think FRED has (arrived yet).
b. *It isn't the wine that PETER drank, it's the wine that JOHN drank.

The former is ungrammatical because it requires a topic expression 'the $\mathrm{x}$ such that I think $x$ has arrived yet', which is un-well-formed. The second sentence is ungrammatical on a cleft reading (not on a relative clause reading) because cleft constructions require that the clefted constituent (wine in this case) be comment, whereas the heavy accent on PETER requires that that is comment.

Moreover, the lowering analysis is also tailor-made for interrogative WH-constituents, as in 
(79) a. What did Susan buy?

This can be analyzed as

(79) b. [be whát (the $x[$ Susan Past-buy $x]$ )]

resulting, by $\mathrm{ACL}$, in

(79) c. Susan Past-buy whát?

Postcyclic WH-fronting then produces (79a). Note that, besides (79a), there are also a cleft and a pseudocleft version:

(79) d. What is it that Susan bought?

e. What Susan bought is what?

That this analysis is far from recherché appears from a number of observations from different languages. French, for example, is a language where ACL has a special status: it is blocked for cases of direct use where the constituent which is contrasted or emphasized is an NP, and it is allowed only for quoted cases where clefting is impossible:

(80) a. Ce n'est pas le VIN que Pierre a bu, c'est le GIN. it is not the WINE that Peter drank it is the GIN

b. *Pierren'a pas bu le VIN, il a bu le GIN Peter didn't drink the WINE he drank the GIN

(81) a. *Cen'est pas CONque son comportementest structif, c'est DÉ. it is not CON thathis behavior is structive it is DE

b. Son comportement n'est pas CONstructif, il est DÉstructif. his behavior is not CONstructive it is DEstructive

French thus maximizes the use of clefts and pseudoclefts. This is exactly paralleled in questions, where cleft and pseudocleft forms are strongly preferred:

(82) a. Qu' est-ce que tu as vu? what is it that you have seen

b. Qui est-ce qui a bu le vin? who is it that drank the wine

Unexpected confirmation comes from a sentence in the Latin author Tacitus (Annals 12.36):

a. Avebantque visere QUIS ille tot per and they wished to come and see WHO that man so many for annos opes nostras sprevisset. years power our had scorned

All commentaries on this text instruct the reader to interpret this 
sentence as though it had been

b. Avebantque visere

QUIS esset ille

qui

and they wished to come and see WHO was that man who

tot per annos opes nostras sprevisset.

so many for years power our had scorned

That is, the sentence means, in good English, 'and they wished to come and see who that man was who for so many years had scorned our power'. (The sentence is about the Britannic freedom fighter Caratacus who had been captured by the Romans and was displayed in Rome.) What has happened is entirely transparent in the lowering analysis. The underlying structure is representable as

c. ... visere [esse quís (ille $\mathrm{x}[\mathrm{x}$ tot per annos opes come and see be whó that so many for years power nostras sprevisset])]

our had scorned

$\mathrm{ACL}$ is, strictly speaking, not allowed here since the subject of esse 'be' is not an ordinary definite NP with the definite article (which is zero in Latin) but a definite NP with the demonstrative pronoun ille 'that', so that the structural conditions of (75) are not met. In fact, (83a) is, strictly speaking, ungrammatical in Latin and is accepted only on account of Tacitus's credit as an author. What Tacitus did when he wrote that sentence (though he could not have been aware of it) is that he forced ACL upon (83c) and simply kept the ille, thus applying his stylistic rule of maximal brevity:

(83) d. ... visere [QUIS ille tot per annos opes nostras sprevisset]

How sentence (83a) could be accounted for without a lowering analysis is totally unclear.

It thus appears that lowering is not a rule invented strictly for the purpose of providing a transformational derivation from RQT formulae to surface sentences. On the contrary, as a rule, or rule schema, it has strong independent rights in syntax. In this connection it is interesting and relevant to note that $\mathrm{ACL}$ is sensitive to SOC to some extent. In German and Dutch the negation stays to the left of any lowered accented constituent if it takes scope over it, just as English not stays left of quantifiers:

(84) a. Nicht die STUDENTEN haben den Polizisten angeklagt, not the STUDENTS have the policeman indicted sondern die PROFESSOREN. but the PROFESSORS 
In English, not stays left of accented constituents only if a but phrase follows immediately:

\section{b. Not the STUDENTS but the PROFESSORS have indicted the policeman.}

This completes the case for the lowering analysis for quantifiers, negation, and logical connectives, and against treatments which do not express the fact that the interpretive processes required for the operators mentioned are strictly parallel to, and in some cases intimately linked up with, rules and processes seen to operate anyhow in the syntax of natural languages.

\section{Conclusion}

It is a curious fact in the theoretical linguistic literature of the past 15 years or so that the lowering analysis has been both maligned and dismissed without any serious argument. Naive bystanders might have expected a keen interest on the part of theoretical linguists in any analysis that would do justice to the surprising discovery that scope hierarchies are nontrivially reflected in left-to-right orderings of the operators concerned. Any theory accounting for this analogy would seem to mark a development of some importance and magnitude, since it would reconcile grammatical and logical analyses after centuries of alienation and estrangement. Not so, however. The lowering analysis was met with indifference, prejudice, and facile dismissal. What factors were responsible for this course of affairs is a question we had perhaps better not go into here, especially because they had little to do with academic principles. All we can do here is signal the fact that a highly inspiring analysis and one of great promise was reduced to undeserved obscurity.

Remarkably little is to be found in the literature in the way of argument against the lowering analysis. Usually one finds an enumeration of misconceptions and/or prejudices, presented as accepted truths, but hardly ever an argument or an attempted argument. Jackendoff (1983) is exceptional in that it contains a few observations that might be taken as an argument against the lowering analysis. On p. 15 one reads,

Naturally there are good reasons for adopting the formalism of quantificational logic, having to do with certain aspects of the inference problem. Yet one could hardly expect a language learner to learn the complex correspondence rules required to relate quantificational formalism to surface syntax. The logician might respond by claiming that this aspect of the correspondence rules is universal and thus need not be learned. But then we could ask on a deeper level why language is 
the way it is: Why does it display the constituent structure and embedding relations it does, if it expresses something formally so different?

Two comments are in order here. First, the learnability aspect is of no relevance here, since, as Jackendoff's imaginary logician says (although the reply is much more typical of the kind of linguistics represented by Jackendoff than of any brand of logical grammar actually on the market), the rules in question may not have to be learned at all. Moreover, who would dare to claim that the rules and translations required in approaches that avoid the intermediate syntactic level of RQT representations are so simple that the question of learnability does not arise? And second, to ask why surface structures are not like predicate calculus (in terms of RQT), or, in other words, why we do not speak in the language of predicate calculus if that language underlies surface structures, is ingenuous to say the least. Whereas QT structures are optimal for logical and semantic calculus, they are badly suited to rapid acoustic transmission. The point of the transformational process from RQT deep structures to linguistic surface structures is mainly a functional one: the 'steep' trees of deep structure, with their numerous embeddings of Ss and very few different categories (only S, V, and NP) are reduced to 'flat' trees with much greater emphasis on left-to-right order and with many different categories, plus an intonational overlay. Since tree structure is not itself transmitted in acoustic verbal communication, it is obviously in the interest of mutual comprehensibility that the role of tree structure in the messages transmitted be kept down as much as possible. This is precisely what the transformational process does.

A footnote is added to the passage just quoted, to be found on p. 242 of the book:

For readers c jnversant in syntactic theory, the argument can be sharpened. There do exist syntactic constructions in natural language that have roughly the form of restricted quantifiers like (1.2b) $<=\exists x$ : Glass [break(Floyd, $\mathrm{x})]>$. Two wellknown examples are questions and relative clauses, in which a preposed $w h$-phrase binds a trace, a gap, or a resumptive pronoun within a clause. On the other hand, there seem to be no natural languages in which an indefinite article triggers such a syntactic construction. The question about (1.2b) thus becomes: If indefinite articles and $w h$ are logically parallel, why is there no pressure for them to be syntactically parallel as well?

This looks a little more like a real argument, but it still lacks any substance. As has been shown, quantifiers and WH-constituents have indeed in common that they are both lowered. They have, moreover, in common that, besides the ordinary lowered versions, there are surface 
representatives not involving lowering:

(85) a. There were some students who drank beer.

b. What is it that Fred was drinking?

But WH-constituents differ from all other lowered elements in that they require postcyclic preposing into the complementizer position. This WHfronting is obligatory if the question is not an 'echo' of a previously uttered sentence, as in

\section{a. Fred was drinking WHAT?}

and if the complementizer position is not already filled, possibly by another WH-constituent, as in

b. WHERE did Susan buy WHAT?

Here, the $W H A T$ cannot be fronted since the complementizer position has already been filled by $W H E R E$. To say that the fronted position of a WH-constituent is of 'roughly the form of restricted quantifiers' may sound attractive, but it is deceptive. There is absolutely no reason why the part did Susan buy of

\section{WHAT did Susan buy?}

should be considered a separate $\mathrm{S}$ structure, distinct from the WHconstituent WHAT, whereas, of course, the propositional nucleus in RQT formulae is an $\mathbf{S}$ structure. Moreover, and perhaps more forcefully, quantifiers differ essentially from preposed WH-constituents in that the former allow for multiple concatenations whereas the latter do not:

\footnotetext{
a. $\exists x$ : Child $\forall y:$ Footballer $[k n o w(x, y)] \Rightarrow$ Some children know all footballers.

b. *WHERE WHAT did Susan buy?
}

It is thus not at all to the point to ask why indefinite articles and WHconstituents are not syntactically parallel, given their logical similarity. The logical similarity is not expressed by the regular sentence-initial position of WH-constituents, but by the lowering analysis which is plausibly postulated for both. This logical similarity is thus strikingly paralleled by similarity in syntactic treatment. The eventual fronting of WH-constituents is a peculiarity of these constituents belonging to the postcycle and not paralleled by the other operators that are also lowered. But if the postcycle is drawn into the discussion, the argument loses all force in view of the many idiosyncrasies and categorial differences in the treatment of the various categories of lowered operators in that part of the grammar. 
In the absence of any better argument against the lowering analysis, it would seem that this analysis carries the day.

Received 10 December 1984

\author{
University of Nijmegen \\ Institute of Philosophy \\ P.O. Box 9108 \\ 6500 HK Nijmegen \\ The Netherlands
}

\section{Notes}

1. Cyclic conjunction reduction, or, as it is called in Seuren (1985), conjunction reduction mapping (CRM), is to be distinguished from gapping, which is postcyclic. Gapping occurs typically when the nonidentical parts are discontinuous and do not contain a verb form, while the identical part contains the verb. Cyclic CRM occurs typically when the identical parts are discontinuous and the nonidentical part is limited and continuous, as in

(i) John washed his hands in the basin and John washed his feet in the basin $\Rightarrow$ John washed his hands and his feet in the basin.

If there is more than one nonidentical part, multiple conjunction reduction may be applied, with respectively added:

(ii) John washed his hands in the basin and Ted washed his feet in the basin $\Rightarrow$ John and Ted washed their hands and their feet, respectively, in the basin.

But in such cases gapping is more appropriate:

(iii) John washed his hands in the basin, and Ted his feet.

Note that cyclic CRM is free to 'split' more than just the minimal nonidentical part or parts. It may even take the whole of both Ss as being nonidentical and thus produce full sentence conjunction, as in (iv), or it may take the VPs as being nonidentical, as in (v), or it may take the object NPs as nonidentical, as in (vi):

(iv) John washed his hands and John washed his feet.

(v) John washed his hands and washed his feet.

(vi) John washed his hands and his feet.

2. McCawley's (1970b) VSO analysis of all surface SVO languages is adopted here, as in Seuren 1985. There is one difference with respect to McCawley's analysis (cf. Seuren 1985; section 2.3.2), in that the conversion from VSO to SVO is considered to be triggered by the verbal tenses. These are analyzed as abstract higher predicates; they are marked for (a) subject raising, and (b) operator lowering (adjoining themselves to the lower V). The result is automatically SVO, or more precisely, NP-VP.

3. In May (1977) the converse of the lowering analysis is proposed in the form of an otherwise equivalent raising analysis (but without any references to preceding work in the lowering analysis). May proposes a so-called 'logical form' (LF) in terms of RQT, related to surface structure by GRAMMATICAL transformations (they are even con- 
sidered part of 'core grammar'). Surprisingly, then, a different 'logical form' (LF') is also proposed, this time in terms of UQT, and intended as input to semantic processing. The relation between $\mathrm{LF}$ and $\mathrm{LF}^{\prime}$, though clearly of a structural nature, is now not considered part of ('core') grammar but is presented as a 'conversion' (1977: 27), outside grammar. Apart from the alacrity with which such notions are introduced and left unexplained, it is clear that no serious account is taken of the logical differences between UQT and RQT.

4. For details of the three-valued calculus employed, see the Appendix by A. Weijters in Seuren (1985).

5. Negative raising is the name of a transformational rule whereby the negation is lifted from a lower clause into the main clause, as in

(i) I don't think he has anything to say.

This rule is discussed more fully in section 5.4 below, where it will be argued that this process of negative raising applies also to certain abstract predicates, including the universal quantifier. These abstract predicates have the extra property that, normally speaking, they change lexically into their logical counterpart. Thus, 'all - not' is changed by negative raising into 'not - any'.

6. It appears from the literature that there is quite a bit of misunderstanding about the details of the lowering analysis. For example, Asher (1984) seems to be under the impression that the semantic differences between (8a) and (8b), or (24a) and (24b), speak against the lowering analysis. This author apparently fails to see that such systematic differences confirm the lowering analysis rather than weaken it.

7. The expression given in (26b) is a daily recurring pun in The Fiji Times. Any reader who bears in mind the fact that Fiji is just west of the date line (which makes a cut into the Western hemisphere to allow Fiji to be part of the Eastern hemisphere) will realize that the intended meaning of this phrase in that newspaper is the secondary reading, which equals the primary reading of (26a).

8. It seems to be the case that in newspaper headlines, as well as in the language used in telegrams, only the primary readings occur and not the secondary ones. In other words, if this observation is correct it would appear that newspaper headlines and telegrams obey SOC more strictly than the fuller uses of natural language found in less inhibited texts.

9. The infinitival strings in question are well known to anyone with only a slight familiarity with German or Dutch:

(i) Ich hätte es ihm zu geben versuchen wollen werden.

I would have it him to give try want will

(ii) I k had het hem zullen willen proberen te geven.

I would have it him will want try to give

'I would have been about to want to try to give it to him.'

Anyone who knows both German and Dutch will also easily recognize the fact that the infinitival strings in question are mirror-ordered in German and Dutch: in German the predicate with the largest scope goes to the right, whereas in Dutch it goes to the left. It has been shown beyond reasonable doubt (Seuren 1972; Evers 1975; Seuren 1985) that such infinitival strings are the result of predicate raising, whereby the higher predicate attracts the lower predicate and attaches it either to the left (German) or to the right (Dutch) of itself, with the automatic consequence that whatever is also dominated by the lower $\mathrm{S}$, apart from the raised predicate, is reattached to the higher $\mathrm{S}$. 
10. In Seuren (1985) it is argued extensively that these negations are instances of the radical negation, which turns radical falsity (resulting from presupposition failure) into truth but assigns minimal falsity to true and minimally false sentences. It is also argued there that the radical negation can only take highest scope.

11. Note that no form of special accent is of any avail to the existential quantifier if it wants largest scope when it is preceded by the negation, as in $(27 \mathrm{~h})$ where the negation is manifested as keine 'no', or in

(i) Luise kann nicht zwei Bücher gelesen haben.

where the negation can be interpreted radically (with accent) but which otherwise, with minimal negation, has the readings (27e) and (27f), but not $(27 \mathrm{~g})$, due, no doubt, to the fact that kann nicht is either Poss - not or not - Poss, but nothing else. The fact that the surface order negation - quantifier cannot be reversed in semantic analysis in German and Dutch follows directly from the fact that the negation lands at the far right of the nucleus if there are no obstacles put in its way by SOC, and the fact that quantifiers are necessarily lowered into the position of the variable bound by them. Thus, an underlying structure of the form 'not [V ...x...]' ends up, after lowering of not, as ' $[\mathrm{V} . . \mathrm{x} . . . \mathrm{not}]$ ', and any higher quantifier binding $x$ will end up in the position of $x$, hence to the left of not. However, an underlying structure of the form 'not [V ...QU...]' (where 'QU' stands for an already lowered quantifier) will necessarily end up as '[V ... not QU ...]', since the negation is not allowed to 'jump over' QU. It follows that the surface order negation - quantifier is semantically fixed for Dutch and German. This fact is, again, reinforcement for the lowering analysis. The Montaguetype analysis is, generally, vulnerable to detailed inspection of the facts. Whereas the global idea of ordered factorizing out of operators by semantic composition and translation may seem attractive, it proves to be counterproductive in the light of close and detailed observation of the relevant facts.

12. If the abstract predicates responsible for tense, aspect, or mood are indeed treated as lowering predicates, something must be done about their behavior with respect to SOC. Their landing site is invariably the lower V, yet scope problems are not known to exist. Given this, some provision must be made ensuring that such semantic predicates are exempt from SOC. Maybe SOC should be formulated in such a way that it applies only to lexical semantic predicates that are lowered into their argument $S$, in the sense of 'lexical' used in the present paragraph.

13. The constraint in question applies only to movement of material into or out of adverbial clauses, not to deletion of material controlled by an element outside such clauses, as appears from cases like

(i) If faulty, the set must be sent back.

Haegeman (1984: 232) quotes a few sentences from early Modern English literature (taken from Visser 1963 and Jespersen 1931) that seem accountable for by deletion, rather than by a violation of the movement constraint:

(ii) A quality ... which, if we could obtain, would add nothing to our honor.

(iii) A man whom if you know you must love.

Note that these sentences are grammatical in present-day English if an anaphoric pronoun is added to the adverbial clauses in question (if we could obtain it / if you know him). This suggests a deletion rule in that variety of English. In Latin (Kühner and Stegmann 1955: 315-316) WH-fronting out of an adverbial clause is allowed (note that 
pronoun suppletion does not work in these cases):

(iv) ... Simonide, de quo quaesivisset... Hiero, deliberandi sibi Simonides, about whom when had asked ... Hiero, to deliberate for himself unum diem postulavit.

one day (he) demanded

i.e. 'Simonides, who when Hiero had asked about, he demanded a day to deliberate for himself.'

(v) omnia perfecit, quae senatus ne fieri possent providerat. everything (he) did, that the senate lest happen could had provided i.e. 'he did everything that the senate had taken steps so that could not happen.'

It is possible that the type of sentence in early Modern English illustrated in (ii) and (iii) is influenced by Latin, which was widely studied and used in those days. If that is the case, English seems to have imitated Latin not by violating the movement constraint operative in English, but by extending the range of deletion phenomena.

14. The only clear counterexample I have been able to find to the claim that quantifier scope is limited to adverbial clauses in which quantified phrases occur is provided by any in when clauses. Consider, for example,

(i) He gets excited when ANY girl looks at him.

where the quantifier represented by any clearly takes scope over the whole sentence. Other kinds of adverbial clause do not seem to allow for such wide scope reading. Take, for example, a because clause, as in

(ii) He gets excited because ANY girl looks at him.

This is interpretable only with any taking scope over the subordinate clause, no matter how heavy an accent is placed on any. It is, at the present stage of the enquiry into such matters, entirely opaque why this should be so. The answer may turn out to lie in some special characteristic of when, or of any (or both). But it may also be the case that this and possible similar refractory cases will turn out to be the key to entirely new insights into the grammar of quantifiers.

15. Geach (1972: 99) presents a counterexample to the claim that quantifiers in relative clauses cannot take scope outside the clause in which they occur. His example, which is presented in a slightly different context, is

(i) The woman whom every true Englishman most reveres is his mother.

This sentence is clearly interpretable with the universal quantifier taking scope over the whole sentence, not just the relative clause. (Geach then wants [1972: 100] to carry the point further by forcing upon a sentence like

(ii) The man who stole a (certain) book from Snead made a lot of money by selling it.

a reading where the existential quantifier represented by $a$ (certain) book likewise has scope over the whole sentence. This, however, seems an erroneous observation.) Note, however, that the subject NP of (i) is not a referring NP but an NP indicating a parameter, whereas the predicate expresses the value assigned to the parameter (and is not an identity predicate). Sentence (i) is thus comparable to sentences like

(iii) The temperature is 20 degrees.

(iv) His name is Charley.

(v) The number of planets is 9 . 
where no identity is involved, but value assignment to parameters. This distinction between referring NPs and parameter NPs seems to matter in this respect, as appears from a sentence like

(vi) The woman whom every true Englishman most reveres is the Queen.

where the subject NP is indeed a referring NP and where the only possible interpretation limits the scope of the universal quantifier to the relative clause. Why this distinction should have this consequence is a question to which no answer is available at the present moment.

16. A factive predicate has the special property that it makes sentences in which it occurs presuppose the truth of the that clause with respect to which the predicate is factive. (Some verbs take that clauses in subject as well as in object position [see (39) below]; in those cases the subject clause is always factive.) The first (to my knowledge) to distinguish the category of factive predicates (verbs) was Frege (1892). Kiparsky and Kiparsky (1971) established the factive predicates (except know) as a separate grammatical category and introduced the term 'factive'.

17. Just as in English the combination can't of not plus the agentive modal can is grammatically raised over seem, as in

(i) I can't seem to find it.

which clearly means 'it seems that I cannot find it', or something closely analogous.

18. A similar treatment, but without lexical switch, is proposed in Seuren (1974) for punctual until, as in

(i) She didn't post the letter until 4 o'clock.

which means 'until 4 o'clock it was not the case that she posted the letter'. Note that, in spite of the semantic lower scope of not, its grammatical position is well-anchored to the left of until, as appears from the fronting of the until phrase:

(ii) Not until 4 o'clock did she post the letter.

(iii) *Until 4 o'clock she didn't post the letter.

It is highly significant that Bree (in Bree i.p., which is the most meticulous study available to date on the uses of until and since in English) is forced to admit that punctual until cannot be fitted in with the other uses of until to make for a coherently structured field of uses: under no thinkable analysis can this unification be achieved. However, Brée does not take into account the possibility of raising the negation over until, as proposed here. With this extra assumption the problem is easily solved. Notice, moreover, that in certain varieties of English the universal quantifier shows up in the form of all even though it stands under some form of negation and the meaning is 'all - not', as in

(iv) I heard fuckall.

meaning 'I heard nothing'. The prefix to all may be considered a lexical manifestation of the negation in this class of cases.

19. Interestingly, halfway CRM, not involving not, is also possible with and:

(i) She doesn't like tea and doesn't like coffee.

This provides further grounds for the assumption that there is a close connection between the negative raising force of AND (changing into OR) on the one hand, and the collapsing of two negations under CRM on the other. 


\section{References}

Asher, N. (1984). Meanings don't grow on trees. Journal of Semantics 3 (3), 229-247.

Barwise, J., and Cooper, J. (1981). Generalized quantifiers and natural language. Linguistics and Philosophy 4 (2), 159-219.

Brée, D. (i.p.). The durative temporal subordinating conjunctions since and until. Journal of Semantics 3 (4).

Davidson, D., and Harman, G. (eds.) (1972). Semantics of Natural Language. Dordrecht: Reidel.

Evers, A. (1975). The transformational cycle in Dutch and German. Unpublished Ph.D. thesis, University of Utrecht.

Frege, G. (1879). Begriffsschrift. Eine der arithmetischen nachgebildete Formelsprache des reinen Denkens. Halle a.S.: Nebert.

-(1892). Ueber Sinn und Bedeutung. Zeitschrift für Philosophie und philosophische Kritik $100,25-50$.

Garvin, P. M. (ed.) (1970). Cognition: A Multiple View. New York: Spartan.

Geach, P. T. (1962). Reference and Generality. An Examination of Some Medieval and Modern Theories. Ithaca, N.Y.: Cornell University Press.

-(1972). Logic Matters. Oxford: Blackwell.

Haegeman, L. (1984). Parasitic gaps and adverbial clauses. Journal of Linguistics 20 (2), 229-232.

Jackendoff, R. (1983). Semantics and Cognition. Cambridge, Mass.: MIT Press.

Jespersen, O. (1931). A Modern English Grammar on Historical Principles, III.2. London: Allen and Unwin.

Katz, J. J., and Postal, P. M. (1964). An Integrated Theory of Linguistics Descriptions. Cambridge, Mass.: MIT Press.

Kiparsky, P., and Kiparsky, C. (1971). Fact. In D. D. Steinberg and L. A. Jakobovitz (eds.), Semantics, 345-369. Cambridge: Cambridge University Press.

Kühner, R., and Stegmann, C. (1955). Ausführliche Grammatik der lateinischen Sprache. Satzlehre II (anastatic reprint). Leverkusen: Gottschalk.

Lakoff, G. (1969). On derivational constraints. Chicago Linguistic Society 5, 117-139.

-(1971). On generative semantics. In D. D. Steinberg and L. A. Jakobovitz (eds.), Semantics, 232-296. Cambridge: Cambridge University Press.

May, R. (1977). The grammar of quantification. Unpublished Ph.D. dissertation, MIT.

McCawley, J. D. (1970a). Semantic representation. In P. M. Garvin (ed.), Cognition, 227-247. New York: Spartan.

-(1970b). English as a VSO-language. Language 46 (2), 286-299.

- (1972). A program for logic. In D. Davidson and G. Harman (eds.), Semantics of Natural Language, 498-544. Dordrecht: Reidel.

-(1973). Grammar and Meaning. Papers on Syntactic and Semantic Topics. Tokyo: Taishukan.

-(1981). Everything that Linguists have Always Wanted to Know About Logic (but Were Ashamed to Ask). Oxford. Blackwell.

Montague, R. (1974). Formal Philosophy. Selected Papers of Richard Montague, edited and with an introduction by Richmond $\mathrm{H}$. Thomason. New Haven and London: Yale University Press.

Ross, J. R. (1967). Constraints on variables in syntax. Unpublished Ph.D. dissertation, MIT.

Russell, B. (1905). On denoting. Mind 14, 479-493. 
Seuren, P. A. M. (1967). Negation in Dutch. Neophilologus 51 (4), 327-363.

-(1969). Operators and Nucleus. A Contribution to the Theory of Grammar. Cambridge: Cambridge University Press.

- (1972). Predicate raising and dative in French and sundry languages. Unpublished paper, Magdalen College, Oxford.

-1974). Negative's travels. In P. Seuren (ed.), Semantic Syntax, 183-208. Oxford: Oxford University Press.

- (1985). Discourse Semantics. Oxford: Blackwell.

-(ed.) (1974). Semantic Syntax. Oxford Readings in Philosophy. Oxford: Oxford University Press.

Steinberg, D. D., and Jakobovits, L. A. (eds.) (1971). Semantics. An Interdisciplinary Reader in Philosophy, Linguistics, and Psychology. Cambridge: Cambridge University Press.

Van Oirsouw, R. R. (1980). Deletion processes in coordinate structures in English. Unpublished Ph.D. thesis, Cambridge University.

- (1984). Accessibility of deletion in Dutch. Journal of Semantics 3 (3), 201-227.

Visser, F. T. (1963). An Historical Syntax of the English Language, vol. 1. Leiden: Brill. 
